\title{
Effect of Hall Currents and Non-Linear Density Temperature Variation on Convective Heat and Mass Transfer Flow of a Viscous Fluid past a Stretching Sheet with Thermo- Diffusion, Chemical Reaction and Heat Source
}

\author{
Shaik Sharmila ${ }^{1}$, R. Mabunni ${ }^{\# 2}$ and Prof. R. Siva Prasad ${ }^{1}$ \\ ${ }^{1}$ Department of Mathematics,Sri Krishnadevaraya University, Ananthapuramu-515003, Andhra Pradesh, India \\ Email : gousehalima@gmail.com \\ 2 School Asst., ZPHS Maidukur (M), YSR (Dist., Andhra Pradesh, India
}

\begin{abstract}
In this Paper, we study the combined influence of chemical reaction, Hall currents and Soret effect on convective heat and mass transfer flow of a viscous electrically conducting fluid past a stretching sheet. The equations governing the flow of heat and mass transfer have been solved by Galerkin finite element analysis with three nodded line segments. The velocity, temperature and concentration have been analysed for different values of M, m, N, Sc and So. The rate of heat and mass transfer on the plate has been evaluated numerically for different variations.
\end{abstract}

Keywords: Hall Currents, Non-Linear Density Temperature, Heat and Mass Transfer, Stretching Sheet, ThermoDiffusion, Chemical Reaction, Heat Source

\section{INTRODUCTION}

Laminar boundary layer behavior over a moving continuous and linearly stretching surface is a significant type of flow has considerable practical applications in engineering, electrochemistry (Chin [13], Gorla [20]) and polymer processing, (Griffith [21], Erickson et. al. [18]). For example, materials manufactured by extrusion process and heat treated materials traveling between a feed roll and a windup roll or on a conveyor belt possesses the characteristics of a moving continuous surface. The hydromagnetic flow and heat transfer problems have become important industrially. To be more specific, it may be pointed out that many metallurgical processes involve the cooling of continuous strips or filaments by drawing them through a quiescent fluid and that in the process of drawing, these strips are sometimes stretched. Mention may be made of drawing, annealing and tinning of copper wires. In all the cases the properties of the final product depend to a great extent on the rate of cooling. By drawing such strips in an electrically conducting fluid subjected to magnetic fluid, the rate of cooling can be controlled and a final product of desired characteristics can be achieved. Another interesting application of hydromagnetics to metallurgy lies in the purification of molten metals from nonmetallic inclusions by the application of a magnetic field. The study of heat and mass transfer is necessary for the determining the quantity of the final product. However, there are fluids, which react chemically with some other ingredients present in them. The effect of a chemical reaction on the flow past an impulsively started infinite vertical plate with uniform heat flux was studied by Das et.al. [16], Anderson et. al. [6], have studied the diffusion of a chemical reactive species from a linearly stretching sheet. Anjalidevi and Kandaswamy [7] have investigated the effect of a chemical reaction on the flow along a semi infinite horizontal plate in the presence of heat transfer. Anjalidevi and Kandaswamy
[8] have studied the effect of a chemical reaction on the flow in the presence of heat transfer and magnetic filed. Muthukumaraswamy and Ganesan [30] have analyzed the effect of a chemical reaction on the unsteady flow past on impulsively started semi-infinite vertical plate, which is subject to uniform heat flux. McLeod and Rajagopal [28] have investigated the uniqueness of the flow of a Navier Stoke's fluid due to a linear stretching boundary. Raptis et. al. [33], have studied the viscous flow over a non-linearly stretched sheet in the presence of a chemical reaction and magnetic field.

In 1961, Sakiadis [36] who developed a numerical solution for the boundary layer flow field over a continuous solid surface moving with constant speed. Due to entertainment of ambient fluid, this boundary layer flow situation is quite different from the classical blasius problem over a semi-infinite flat plate. Suction or injection of a stretched surface was studied by Erickson et.al. [18], and Fox et.al. [19] for uniform velocity and temperature and investigates its effects on the heat and mass transfer in the boundary layer. Chen and Char [12] have studied the suction and injection on a linearly moving plate subject to uniform wall temperature and heat flux and the more general case using a power law velocity and temperature distribution at the surface was studied by Ali [5]. Magyari et.al. [26] have reported analytical and computational solution when the surface moves with rapidly decreasing velocities using the self-similar method. In all the papers mentioned above the effect of buoyancy force was relaxed. The above investigations having a definite bearing on the problem of a Polymer sheet extruded continuously from a dye. It is usually assumed that the sheet is in extensible, but situations may arise in the polymer industry in which it is necessary to deal with a stretching plastic sheet, as noted by Crane [15]. The study of heat generation or absorption in moving fluids is important in the problems dealing with chemical reactions and these concerned with dissociating 


\section{International Journal of Research in Advent Technology, Vol.7, No.4, April 2019 E-ISSN: 2321-9637 \\ Available online at www.ijrat.org}

distribution. Consequently, the practice deposition rate in nuclear reactors, electronic chips and semi conductor waves. Vajravelu and Hadjinicolaou [42] have studied the heat characteristics in the laminar boundary layer of a viscous fluid over a stretching sheet with viscous dissipation or frictional heating and internal heat generation. Mohebujjaman et.al. [29] have studied the MHD heat transfer mixed convection flow along a vertical stretching sheet in presence of magnetic field with heat generation. Sajid et.al. [35] have discussed the non-similar analytic solution for MHD flow and heat transfer in a third-order fluid over a stretching sheet. Biliana et.al. [9] have analyzed the numerical solution of the boundary layer flow over an exponentially stretching sheet with thermal radiation. Jat et.al. [25] have studied the MHD flow and heat transfer over a stretching sheet.

The effect of chemical reaction on free convective flow and mass transfer of a viscous, incompressible and electrically conducting fluid over a stretching sheet was investigated by Afify [4] in the presence of a transverse magnetic field. In all these investigations the electrical conductivity of the fluid was assumed to be uniform. However, in an ionized fluid where the density is low and/or magnetic field is very strong, the conductivity normal to the magnetic field is reduced due to the spiraling of electrons and ions about the magnetic lines of force before collisions take place and a current induced in a direction normal to both the electric and magnetic fields. This phenomenon available in the literature is known as Hall Effect. Thus the study of MHD viscous flows, heat and mass transfer with Hall currents has important bearing in the engineering applications.

Hall effect on MHD boundary layer flow over a continues semi-infinite flat plate moving with a uniform velocity in its own plane in an incompressible viscous and electrically conducting fluid in the presence of a uniform transverse magnetic field were investigated by Watanabe and Pop [44]. Abo-Eldahab [1] have investigated free convective flows past a semi-infinite vertical plate with mass transfer. The effect of Hall current on the study MHD flow of an electrically conducting, incompressible Burger's fluid between two parallel electrically insulating infinite plane was studied by Rana et. al. [32].

Samadh et. al. [37] have studied MHD heat and mass transfer free convection flow along a vertical stretching sheet in the presence of magnetic field with heat generation. Seddeek [38] have studied the heat and mass transfer on a stretching sheet with a magnetic field in a visco-elastic fluid flow through a porous medium with heat source or sink. Veena et.al. [43] have discussed the non-similar solutions for heat and mass transfer flow in an electrically conducting visco-elastic fluid over a stretching sheet embedded in a porous medium. Hsiao has analysed the heat and mass transfer for electrical conducting mixed convection with radiation effect for visco-elastic fluid past a stretching sheet. Shit [39] has studied Hall effects on MHD free convective flow on mass transfer over a stretching sheet. Raghavendra Rao [31] has discussed the effect of chemical reaction, Hall effects on the convective heat and mass transfer flow past a stretching sheet.

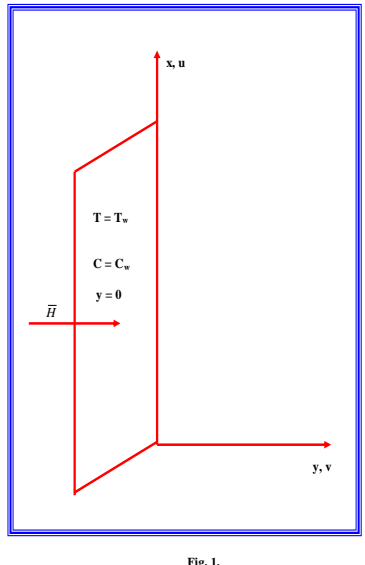

In all above studies the thermal -diffusion effect (Soret effect) has been neglected. This assumption is true when the concentration level is very low. There are, however, exemptions. The Soret effect for instance, has been utilized for isotope separation and in mixtures between gases with very low molecular weight $(\mathrm{H} 2, \mathrm{He})$ and the medium molecular weight (N2,air) the Soret effect was found to be of a magnitude just it can not be neglected. (Eckert and Drake [17]). In view of the importance of this Soret effect, the free convection and mass transfer flow in an infinite vertical plate moving impulsively in its own plane, taking into the account of Soret effect. Abdul Sattar and Alam [2] have considered an unsteady convection and mass transfer flow of viscous incompressible fluid and electrically conducting fluid past a moving infinite vertical porous plate taking into the thermal diffusion effect. Similarity equations of momentum, energy and concentration equations are derived by introducing a time dependent length scale. Malsetty et al [27] studied the effect of both Soret and Dufour effects on the double diffusive convection with compensating horizontal and thermal and solute gradients. Ajay Kumar Singh[3] studied the study free convection and mass transfer flow with Hall Effect, viscous dissipation and joule heating, taking into account the thermal diffusion effect. Sreevani [41] has analyzed the free convective heat and mass transfer flow of a viscous incompressible fluid through a porous medium confined in vertical channel in the presence of constant heat source Q bounded by flat plates. Reddaiah et al [34] have discussed dissipative and Soret effect on convective heat and mass transfer through a porous medium in a vertical channel maintained at Non uniform temperature. Sreenivasa reddy [40] have discussed mixed convective heat and mass transfer through a porous medium in a channel with variable permeability and Soret effect. Reddaiah has considered finite element analysis of convective heat and mass transfer through a porous medium in horizontal porous channel with dissipative and Soret effects. 


\section{Available online at www.ijrat.org}

\section{FORMULATION OF THE PROBLEM:}

We consider the steady flow of an incompressible, viscous ,electrically conducting fluid past a flat surface which is assuming from a horizontal slit on a vertical surface and is stretched with a velocity proportional to distance from a fixed origin $\mathrm{O}$. We choose a stationary frame of reference $\mathrm{O}(\mathrm{x}, \mathrm{y}, \mathrm{z})$ such that $\mathrm{x}$-axis is along the direction of motion of the stretching surface, $y$-axis is normal to this surface and $\mathrm{z}$-axis is transverse to the xy-plane. A uniform magnetic field in the presence of fluid flow induces the current $\left(J_{x}, 0, J_{z}\right)$.

When the strength of the magnetic field is very large we include the Hall current so that the generalized Ohm's law (Cowling[12]) is modified to

$\bar{J}+\omega_{e} \tau_{e} \bar{J} x \bar{H}=\sigma\left(\bar{E}+\mu_{e} \bar{q} x \bar{H}\right)$

where $\bar{q}$ is the velocity vector. $\mathrm{H}$ is the magnetic field intensity vector. $\bar{E}$ is the electric field, $\bar{j}$ is the current density vector, $\omega_{e}$ is the cyclotron frequency, $\tau_{e}$ is the electron collision time, $\sigma$ is the fluid conductivity and $\mu_{e}$ is the magnetic permeability. The effect of Hall current give rise to a force in the z-direction which in turn produces a cross flow velocity in this direction and thus the flow becomes three -dimensional. To simplify the analysis, we assume that the flow quantities do not vary along $\mathrm{z}$-direction and this will be valid if the surface is of very width along the z-direction. Neglecting the electron pressure gradient, ion-slip and thermo-electric effects and assuming the electric field $\mathrm{E}=0$, equation (2.1) reduces

$j_{x}-m H_{0} J_{z}=-\sigma \mu_{e} H_{0} w$

$J_{z}+m H_{0} J_{x}=\sigma \mu_{e} H_{0} u$

where $\mathrm{m}=\omega_{e} \tau_{e}$ is the Hall parameter.

On solving equations (2.2)\&(2.3) we obtain

$$
\begin{aligned}
& j_{x}=-\frac{\sigma \mu_{e}^{2} H_{0}^{2}}{1+m^{2}}(m u-w) \\
& j_{z}=\frac{\sigma \mu_{e}^{2} H_{o}^{2}}{1+m^{2}}(u+m w)
\end{aligned}
$$

where $\mathrm{u}, \mathrm{w}$ are the velocity components along $\mathrm{x}$ and $\mathrm{z}$ directions respectively,

The equation of Continuity is

$$
\frac{\partial u}{\partial x}+\frac{\partial v}{\partial y}=0
$$

The Momentum equations are

$$
\begin{aligned}
& u \frac{\partial u}{\partial x}+v \frac{\partial u}{\partial z}=-\frac{\partial p}{\partial x}+v \frac{\partial^{2} u}{\partial y^{2}}-\mu_{e} H_{0} J_{z}-\rho \bar{g} \\
& u \frac{\partial W}{\partial x}+v \frac{\partial W}{\partial y}=v \frac{\partial^{2} W}{\partial y^{2}}+\mu_{e} H_{0} J_{x}
\end{aligned}
$$

$$
\rho C_{p}\left(u \frac{\partial T}{\partial x}+w \frac{\partial T}{\partial z}\right)=k_{f} \frac{\partial^{2} T}{\partial y^{2}}+Q\left(T-T_{\infty}\right)
$$

The diffusion equation is

$$
\left(u \frac{\partial C}{\partial x}+v \frac{\partial C}{\partial y}\right)=D \frac{\partial^{2} C}{\partial y^{2}}-k_{0}\left(C-C_{\infty}\right)+k_{11} \frac{\partial^{2} C}{\partial y^{2}}
$$

The equation of state is

$$
\rho-\rho_{0}=-\beta_{0}\left(T-T_{\infty}\right)-\beta_{1}\left(T-T_{\infty}\right)^{2}-\beta^{\bullet}\left(C-C_{\infty}\right)
$$

Substituting $\mathrm{J}_{\mathrm{x}}$ and $\mathrm{J}_{\mathrm{z}}$ from equations (2.4) \& (2.5) in equations (2.7)\&(2.8) we obtain

$$
\begin{aligned}
& u \frac{\partial u}{\partial x}+v \frac{\partial u}{\partial y}=v \frac{\partial^{2} u}{\partial y^{2}}-\frac{\sigma \mu_{e} H_{0}^{2}}{1+m^{2}}+\beta_{0} g\left(T-T_{\infty}\right)+ \\
& +\beta_{1} g\left(T-T_{\infty}\right)^{2}+\beta^{\bullet} g\left(C-C_{\infty}\right) \\
& \left.u \frac{\partial w}{\partial x}+v \frac{\partial w}{\partial y}=v \frac{\partial^{2} w}{\partial y^{2}}\right)+\frac{\sigma \mu_{e}^{2} H_{0}^{2}}{1+m^{2}}\left(m_{0} u-w\right)
\end{aligned}
$$

where $\mathrm{T}$ is the temperature and $\mathrm{C}$ is the concentration in the fluid. $\mathrm{k}_{\mathrm{f}}$ is the thermal conductivity, $\mathrm{Cp}$ is the specific heat at constant pressure, $\beta_{0} \& \beta_{1}$ is the coefficient of thermal expansion, $\beta^{\bullet}$ is the volumetric expansion with concentration, $Q_{1}^{1}$ is the radiation absorption coefficient, $\mathrm{q}_{\mathrm{r}}$ is the radiative heat flux, $\mathrm{k}_{0}$ is the chemical reaction coefficient, $\mathrm{D}$ is the molecular viscosity, $\sigma^{*}$ is the Stephen Boltzmann constant, $\beta_{R}$ is the mean absorption coefficient.

The boundary conditions for this problem can be written as

$$
\begin{aligned}
& u=b x, v=w=0, T=T_{w}, C=C_{w} \text { at } y=0 \\
& u=w=0, T=T_{\infty}, C=C_{\infty} \text { as } y \rightarrow \infty
\end{aligned}
$$

Where $b>0$.The boundary conditions on the velocity in (2.17) are the no-slip conditions at the surface at $\mathrm{y}=0$, while the boundary conditions on the velocity as $y \rightarrow \infty$ follow from the fact that there is no flow far away from the stretching surface. The temperature and species concentration are maintained at a prescribed constant values $\mathrm{T}_{\mathrm{w}}$ and $\mathrm{C}_{\mathrm{w}}$ at the sheet and are assumed to vanish far away from the sheet.

On introducing the similarity variables

$$
\begin{array}{ll}
\eta=\sqrt{\frac{b}{v}} y, & u=b x f^{\prime}(\eta) \\
v=-\sqrt{b v} f(\eta) & w=b x g(\eta) \\
\theta(\eta)=\frac{T-T_{\infty}}{T_{w}-T_{\infty}} & \phi(\eta)=\frac{C-C_{\infty}}{C_{w}-C_{\infty}}
\end{array}
$$

Equations (2.10), (2.12),(2.13) \& (2.16) reduces to

The energy equation is 


$$
\begin{aligned}
& f^{\prime \prime \prime}+f f^{\prime \prime}-f^{\prime 2}+G\left(\theta+\gamma \theta^{2}\right. \\
& +N \phi)-\frac{M^{2}}{1+m^{2}}\left(f^{\prime}+m g\right)=0 \\
& g^{\prime \prime}+f g^{\prime}-\left(f^{\prime}+\frac{M^{2}}{1+m^{2}}\right) g+\frac{m M^{2}}{1+m^{2}} f^{\prime}=0 \\
& \theta^{\prime \prime}+P f \theta^{1}-\alpha \theta=0 \\
& \phi^{\prime \prime}+S c\left(\phi^{\prime} f-\gamma \phi\right)=-\frac{S c S o}{N} \theta^{\prime \prime}
\end{aligned}
$$

and the boundary conditions $(2.17) \&(2.18)$ are now obtained from (2.19) as

$$
\begin{aligned}
& f^{\prime}(0)=1, \quad f(0)=0, \quad \theta(0)=\phi(0)=0 \\
& f^{\prime}(\infty)=g(\infty)=\theta(\infty)=0
\end{aligned}
$$

where

$G=\frac{\beta g\left(T_{w}-T_{\infty}\right)}{b^{2} x}$ (Grashof number),

$M^{2}=\frac{\sigma \mu_{e}^{2} H_{0}^{2}}{b x}$ (Hartmann number)

$N=\frac{\beta^{*}\left(C_{w}-C_{\infty}\right)}{\beta\left(T_{w}-T_{\infty}\right)}$ (Buoyancy

ratio), $S o=\frac{k_{11}\left(T_{w}-T_{\infty}\right)}{b\left(C_{w}-C_{\infty}\right) \nu}$ (Soret parameter)

$S c=\frac{v}{D}$ (Schmidt number), $k=\frac{k_{0}}{b}$ (Chemical

reaction parameter)

For the computational purpose and without loss of generality $\infty$ has been fixed as 8 . The whole domain is divided into 11 line elements of equal width, each element being three nodded.

\section{FINITE ELEMENT ANALYSIS}

The method basically involves the following steps:

(1) Division of the domain into elements, called the finite element mesh.

(2) Generation of the element equations using variational formulations.

(3) Assembly of element equations as in step 2.

(4) Imposition of boundary conditions to the equations obtained in step 3

(5) Solution of the assumed algebraic equations.

The assumed equations can be solved by any of the numerical technique viz. Gaussian elimination, LU Decomposition method etc.

VARIATIONAL FORMULATION : The variational form associated with the equations(2.17)-(2.20)over a typical two nodded line at element $\left(\eta_{e}, \eta_{e+1}\right)$ is given by

$$
\int_{\eta_{e}}^{\eta_{e+1}} w_{1}\left(f^{\prime}-h\right) d \eta=0
$$

$$
\begin{aligned}
& \int_{\eta_{e}}^{\eta_{e+1}} w_{12}\left(h^{\prime \prime}+f h^{\prime}-h^{2}+G\left(\theta+\gamma \theta^{2}+N \phi\right)\right. \\
& -\frac{M^{2}}{1+m^{2}}(h+m g) d \eta=0 \\
& \int_{\eta_{e}}^{\eta_{e+1}} w_{3}\left(g^{\prime \prime}+f g^{\prime}-\left(h+\frac{M^{2}}{1+m^{2}}\right) g+\frac{m M^{2}}{1+m^{2}} h\right) d \eta=0 \\
& \int_{\eta_{e}}^{\eta_{e+1}} w_{4}\left(\theta^{\prime \prime}+P f \theta^{\prime}-\alpha \theta\right) d \eta=0 \\
& \int_{\eta_{e}}^{\eta_{e+1}} w_{5}\left(\phi^{\prime \prime}+S c\left(\phi^{\prime} f-\gamma \phi\right)-\frac{S c S o}{N} \theta^{\prime \prime}\right) d \eta=0
\end{aligned}
$$

Where w1, w2, w3, w4, w5 are arbitrary test functions and may be regarded as the variations in $\mathrm{f}, \mathrm{h}, \mathrm{g}, \theta$ and $\phi$ respectively.

\section{FINITE ELEMENT FORMULATION}

The finite element method may be obtained from (3.1)-(3.5) by substituting finite element approximations of the form

$$
\begin{aligned}
& f=\sum_{k=1}^{3} f_{k} \psi_{k}, h=\sum_{k=1}^{3} h_{k} \psi_{k}, g=\sum_{k=1}^{3} g_{k} \psi_{k}, \\
& \theta=\sum_{k=1}^{3} \theta_{k} \psi_{k}, \phi=\sum_{k=1}^{3} \phi_{k} \psi_{k}
\end{aligned}
$$

We take $\mathrm{w} 1=\mathrm{w} 2=\mathrm{w} 3=\mathrm{w} 4=\mathrm{w} 5=\psi_{i}^{j}(i, j=1,2,3)(3.7)$ Using (3.7) we can write equations (3.1) - (3.5) as

$$
\begin{aligned}
& \int_{\eta_{e}}^{\eta_{e+1}}\left(\frac{d f}{d \eta}-h\right) \psi_{i}^{j} d \eta=0 \\
& \int_{\eta_{e}}^{\eta_{e+1}}\left(\frac{d}{d \eta}\left(\frac{d h}{d \eta}\right)+f\left(\frac{d h}{d \eta}\right)-h^{2}+G\left(\theta+\gamma \theta^{2}+N \phi\right)\right. \\
& \left.\quad-\frac{M^{2}}{1+m^{2}}(h+m g)\right) \psi_{i}^{j} d \eta=0
\end{aligned}
$$$$
\int_{\eta_{e}}^{\eta_{e+1}} \frac{d}{d \eta}\left(\frac{d g}{d \eta}\right)+f\left(\frac{d g}{d \eta}\right)-\left(h+\frac{M^{2}}{1+m^{2}}\right) g
$$$$
\left.+\frac{m M^{2}}{1+m^{2}} h\right) \psi_{i}^{j} d \eta=0
$$$$
\int_{\eta_{e}}^{\eta_{e+1}}\left(\frac{d}{d \eta}\left(\frac{d \theta}{d \eta}\right)+P f\left(\frac{d \theta}{d \eta}\right)\right) \psi_{i}^{j} d \eta-\alpha \int_{\eta_{e}}^{\eta_{e+1}} \theta \psi_{i}^{j} d \eta=0
$$ 
Available online at $w w w . i j r a t . o r g$

$$
\begin{array}{r}
\int_{\eta_{e}}^{\eta_{e+1}}\left(\frac{d}{d \eta}\left(\frac{d \phi}{d \eta}\right)+S c\left(\left(\frac{d \phi}{d \eta}\right) f-\gamma \phi\right)\right. \\
\left.-\frac{S c S o}{N} \frac{d}{d \eta}\left(\frac{d \theta}{d \eta}\right)\right) \psi_{i}^{j} d \eta=0
\end{array}
$$

Following Galerkine weighted residual method and integration by parts method the equations (3.8)-(3.12) we obtain

$$
\begin{aligned}
& \int_{\eta_{e}}^{\eta_{e+1}}\left(\frac{d f}{d \eta}-h\right) \psi_{i}^{j} d \eta=0 \\
& \int_{\eta_{e}}^{\eta_{e+1}} \frac{d \psi_{i}^{j}}{d \eta}\left(\frac{d h}{d \eta}\right) d \eta-\int_{\eta_{e}}^{\eta_{e+1}} f\left(\frac{d h}{d \eta}\right) \psi_{i}^{j} d \eta \\
& +\int_{\eta_{e}}^{\eta_{e+1}} h^{2} \psi_{i}^{j} d \eta-G \int_{\eta_{e}}^{\eta_{e+1}}\left(\theta+\gamma \theta^{2}+N \phi\right) \psi_{i}^{j} d \eta+ \\
& \int_{\eta_{e}}^{\eta_{e+1}}+\frac{M^{2}}{1+m^{2}} \int_{\eta_{e}}^{\eta_{e+1}}(h+m g) \psi_{i}^{j} d \eta=Q_{1, j}+Q_{2, j} \\
& -Q_{1, j j}=\psi_{j}\left(\eta_{e}\right)\left(\frac{d h}{d \eta}\right)\left(\eta_{e}\right) \\
& Q_{21, j j}=\psi_{j}\left(\eta_{e+1 e}\right)\left(\frac{d h}{d \eta}\right)\left(\eta_{e+1 e}\right)
\end{aligned}
$$

$\int_{\eta_{e}}^{\eta_{e+1}} \frac{d \psi_{i}^{j}}{d \eta} \frac{d g}{d \eta} d \eta-\int_{\eta_{e}}^{\eta_{e+1}} f\left(\frac{d g}{d \eta}\right) \psi_{i}^{j} d \eta$

$+\int_{\eta_{e}}^{\eta_{e+1}}\left(\left(h+\frac{M^{2}}{1+m^{2}}\right) g+\frac{m M^{2}}{1+m^{2}} h\right) \psi_{i}^{j} d \eta=R_{1, j}+R_{2, j}$ where

$$
\begin{gathered}
-R_{1, j}=\psi_{j}\left(\eta_{e}\right) \frac{d g}{d \eta}\left(\eta_{e}\right) \\
R_{2, j}=\psi_{j}\left(\eta_{e+1}\right) \frac{d g}{d \eta}\left(\eta_{e+1}\right)
\end{gathered}
$$

$\int_{\eta_{e}}^{\eta_{e+1}}\left(\frac{d \psi}{d \eta} \frac{d \theta}{d \eta} d \eta-P \int_{\eta_{e}}^{\eta_{e+1}} f\left(\frac{d \theta}{d \eta}\right)\right) \psi_{i}^{j} d \eta-Q_{1} N_{2}$ $\int_{\eta_{e}}^{\eta_{e+1}} \phi \psi_{i}^{j} d \eta=S_{1, j}+S_{2, j}$

$$
\begin{aligned}
-S_{1, j} & =\psi_{j}\left(\eta_{e}\right) \frac{d \theta}{d \eta}\left(\eta_{e}\right) \\
S_{2, j} & =\psi_{j}\left(\eta_{e+1}\right) \frac{d \theta}{d \eta}\left(\eta_{e+1}\right)
\end{aligned}
$$

$$
\begin{aligned}
& \int_{\eta_{e}}^{\eta_{e+1}}\left(\frac{d \psi_{i j}{ }^{j}}{d \eta} \frac{d \phi}{d \eta}-S c\right. \\
& \int_{\eta_{e}}^{\eta_{e+1}}\left(\left(\frac{d \phi}{d \eta}\right) f-\gamma \phi\right) \psi_{i}^{j} d \eta=T_{1, j}+T_{2, j}
\end{aligned}
$$

where

$$
-T_{1, j}=\psi_{j}\left(\eta_{e}\right) \frac{d \phi}{d \eta}\left(\eta_{e}\right) T_{2, j}=\psi_{j}\left(\eta_{e+1}\right) \frac{d \phi}{d \eta}\left(\eta_{e+1}\right)
$$

Expressing $f^{k}, h^{k}, \theta^{k}, \phi^{k}$ in terms of local nodal values (3.14)-(3.17) we obtain

$$
\begin{aligned}
& \int_{\eta_{e}}^{\eta_{e+1}} \sum_{k=1}^{3} h^{k} \int_{\eta_{e}}^{\eta_{e+1}} \frac{d \psi_{i}^{j}}{d \eta}\left(\frac{d \psi_{k}}{d \eta}\right) d \eta \\
& -\sum_{k=1}^{3} f^{k} \int_{\eta_{e}}^{\eta_{e+1}} \psi^{k}\left(\frac{d h}{d \eta}\right) \psi_{i}^{j} d \eta \\
& +\sum_{k=1}^{3}\left(h^{k^{2}}\right) \int_{\eta_{e}}^{\eta_{e+1}} \psi_{k}^{2} \psi_{i}^{j} d \eta- \\
& -G \sum_{k=1}^{3} \int_{\eta_{e}}^{\eta_{e+1}}\left(\theta^{k}+N \phi^{k}\right) \psi_{k} \psi_{i}^{j} d \eta+\frac{M^{2}}{1+m^{2}} \\
& \sum_{k=1}^{3} \int_{\eta_{e}}^{\eta_{e+1}}\left(h^{k}+m g^{k}\right) \psi_{k} \psi_{i}^{j} d \eta=Q_{1, j}+Q_{2, j}
\end{aligned}
$$

where

$$
\begin{aligned}
& -Q_{1, j j}=\psi_{j}\left(\eta_{e}\right)\left(\frac{d h}{d \eta}\right)\left(\eta_{e}\right) \\
& Q_{21, j j}=\psi_{j}\left(\eta_{e+1 e}\right)\left(\frac{d h}{d \eta}\right)\left(\eta_{e+1 e}\right) \\
& \sum_{k=1}^{3} g^{k} \int_{\eta_{e}}^{\eta_{e+1}} \frac{d \psi_{i}^{j}}{d \eta} \frac{d \psi_{k}}{d \eta} d \eta \\
& -\sum_{k=}^{3} f^{k} g^{k} \int_{\eta_{e}}^{\eta_{e+1}}\left(\frac{d \psi_{k}}{d \eta}\right) \psi_{k} \psi_{i}^{j} d \eta \\
& +\sum_{k=1} \int_{\eta_{e}}^{\eta_{e+1}}\left(\left(h^{k}+\frac{M}{1+m^{2}}\right) g^{k}+\frac{m M^{2}}{1+m^{2}} h^{k}\right) \\
& \psi_{k} \psi_{i}^{j} d \eta^{k}=R_{1, j}+R_{2, j} \\
& \text { where } \\
& -R_{1, j}=\psi_{j}\left(\eta_{e}\right) \frac{d g}{d \eta}\left(\eta_{e}\right) \\
& R_{2, j}=\psi_{j}\left(\eta_{e+1}\right) \frac{d g}{d \eta}\left(\eta_{e+1}\right)
\end{aligned}
$$


Available online at www.ijrat.org

$$
\begin{aligned}
& \sum_{k=1}^{3} \theta^{k} \int_{\eta_{e}}^{\eta_{e+1}}\left(\frac{d \psi}{d \eta} \frac{d \psi_{k}}{d \eta} d \eta-P\right. \\
& \left.\sum^{3} \int_{\eta_{e}}^{\eta_{e+1}} f^{k}\left(\frac{d \theta^{k}}{d \eta}\right)\right) \psi_{k} \psi_{i}^{j} d \eta-Q_{1} N_{2} \\
& \sum_{1}^{3} \int_{\eta_{e}}^{\eta_{e+1}} \phi^{k} \psi_{k} \psi_{i}^{j} d \eta=S_{1, j}+S_{2, j}
\end{aligned}
$$

where

$$
\begin{aligned}
& -S_{1, j}=\psi_{j}\left(\eta_{e}\right) \frac{d \theta}{d \eta}\left(\eta_{e}\right) k=1 \\
& S_{2, j}=\psi_{j}\left(\eta_{e+1}\right) \frac{d \theta}{d \eta}\left(\eta_{e+1}\right) \\
& \sum_{k=1}^{3} \phi^{k} \int_{\eta_{e}}^{\eta_{e+1}}\left(\frac{d \psi_{i j}^{j}}{d \eta} \frac{d \psi_{k}}{d \eta}-S c\right.
\end{aligned}
$$$$
\left.\sum_{k=1}^{3} \phi^{k} f^{k} \int_{\eta_{e}}^{\eta_{e+1}}\left(\frac{d \psi_{k}}{d \eta}\right) \psi_{k}-\gamma \phi^{k}\right) \psi_{i}^{j} \psi_{k} d \eta-\frac{S c S o}{N}
$$$$
\sum_{k=1}^{3} \theta^{k} \int_{\eta_{e}}^{\eta_{e}+1}\left(\frac{d \psi_{i j}^{j}}{d \eta} \frac{d \psi_{k}}{d \eta} d \eta=T_{1, j}+T_{2, j}\right.
$$

where

$$
\begin{gathered}
-T_{1, j}=\psi_{j}\left(\eta_{e}\right)\left(\frac{d \phi}{d \eta}\left(\eta_{e}\right)-\frac{S c S o}{N} \frac{d \theta}{d \eta}\left(\eta_{e}\right)\right) \\
T_{2, j}=\psi_{j}\left(\eta_{e+1}\right)\left(\frac{d \phi}{d \eta}\left(\eta_{e+1}\right)-\frac{S c S o}{N} \frac{d \theta}{d \eta}\left(\eta_{e+1}\right)\right)
\end{gathered}
$$

Choosing different $\psi_{i j}^{j}$ corresponding to each element $\eta_{\mathrm{e}}$ in the equation (3.18) yields a local stiffness matrix of order $3 \times 3$ in the form

$$
\begin{aligned}
& \left(f_{i, j}^{k}\right)\left(u_{i}^{k}\right)-G\left(\theta_{i}^{k}+\gamma\left(\theta_{i}^{k}\right)^{2}+N C_{i}^{k}\right) \\
& +\frac{M^{2}}{1+m^{2}}\left(g_{i}^{k}\right)=\left(Q_{1, j}^{k}\right)+\left(Q_{2, j}^{k}\right)
\end{aligned}
$$

Likewise the equations (3.19),(3.20)\&(3.21) give rise to a stiffness matrices

$$
\begin{gathered}
\left(g_{i, j}^{k}\right)+\left(f_{i}^{k}\right)-\frac{m M^{2}}{1+m^{2}}\left(u_{i}^{k}\right)=\left(R_{1, j}^{k}\right)+\left(R_{2, j}^{k}\right) \\
\left(e_{i, j}^{k}\right)\left(\theta_{i}^{k}\right)-P\left(u_{i}^{k}\right)=\left(S_{1, j}^{k}\right)+\left(S_{2, j}^{k}\right) \\
\left(l_{i, j}^{k}\right)\left(\phi_{i}^{k}\right)-S c\left(u_{i}^{k 0}\right)\left(\phi_{i}^{k}\right) \\
-\frac{S c S o}{N}\left(m_{i, j}^{k}\right)\left(\theta_{i}^{k}\right)=\left(T_{1, j}^{k}\right)+\left(T_{2, j}^{k}\right)
\end{gathered}
$$

where $\left(f_{i, j}^{k}\right),\left(g_{i, j}^{k}\right),\left(\theta_{i, j}^{k}\right)\left(\phi_{i, j}^{k}\right),\left(e_{i, j}^{k}\right),\left(l_{i, j}^{k}\right)$, $\left(m_{i, j}^{k}\right)$ are $3 \times 3$ matrices and

$$
\begin{aligned}
& \left(Q_{1, j j}^{k}\right),\left(Q_{2, j j}^{k}\right),\left(R_{1, j j}^{k}\right),\left(R_{1, j j}^{k}\right), \\
& \left(S_{1, j j}^{k}\right),\left(S_{1, j j}^{k}\right),\left(T_{1, j j}^{k}\right) \text { and } .\left(T_{1, j j}^{k}\right)
\end{aligned}
$$

are $3 \times 1$ column matrices and such stiffness matrices (3.22)-(3.25) in terms of local nodes in each element are assembled using inter element continuity and equilibrium conditions to obtain the coupled global matrices in terms of the global node values of $h, f, g, \theta$ and $\phi$.In case we choose $n$ quadratic elements then the global matrices are of order $2 n+1$. The ultimate coupled global matrices are solved to determine the unknown global values of velocity, temperature and concentration in the fluid region. In solving these matrices an iteration procedure has been adopted. The shape functions are

$$
\begin{aligned}
& \psi_{i}^{i}=\frac{(y-8)(y-16)}{128} \\
& \psi_{2}^{1}=\frac{(y-24)(y-32)}{128} \\
& \psi_{3}^{1}=\frac{(y-40)(y-48)}{128} \\
& \psi_{i}^{2 i}=\frac{(y-4)(y-8)}{32} \\
& \psi_{2}^{2}=\frac{(y-12)(y-16)}{32} \\
& \psi_{3}^{2}=\frac{(y-20)(y-24)}{128} \\
& \psi_{3}^{3}=\frac{(3 y-8)(3 y-16)}{128} \\
& \psi_{2}^{5}=\frac{(5 y-24)(5 y-32)}{128} \\
& \psi_{2}^{4}=\frac{(y-6)(y-8)}{8} \\
& \psi_{2}^{3}=\frac{(3 y-24)(3 y-32)}{128} \\
& \psi_{3}^{3}=\frac{(3 y-40)(3 y-48)}{128} \\
& \psi_{i}^{3}=\frac{(5 y-8)(5 y-16)}{128} \\
& \psi_{i}^{3}=(y-12) \\
& 8
\end{aligned}
$$

\section{STIFFNESS MATRICES:}

The global matrix for $\theta$ is

The global matrix for $\phi$ is

$\mathrm{A}_{3} \mathrm{X}_{3}=\mathrm{B}_{3}$

$\mathrm{A}_{4} \mathrm{X}_{4}=\mathrm{B}_{4}$

$\mathrm{A}_{5} \mathrm{X}_{5}=\mathrm{B}_{5}$ 
The global matrix for $\mathrm{f}$ is

The global matrix for $\mathrm{g}$ is

Particular Cases :

1. In the absence of thermo-diffusion $(\mathrm{So}=0)$ the results are good agreeing with Raghavendra Rao [27].

2. In the absence of thermal radiation $\left(\mathrm{N}_{1}=0\right)$, thermodiffusion $(\mathrm{So}=0)$ the results are in agreeing with Shit [34].

\section{DISCUSSION OF THE NUMERICAL RESULTS}

We analyse the effect of chemical reaction, and thermo-diffusion on convective heat and mass transfer flow of a viscous, electrically conducting fluid past a stretching sheet. The non - linear coupled equations are solved by using a finite element technique with three nodded line segments.

The axial velocity $\left(f^{1}(\eta)\right)$ is exhibited in figure 1 for different values of $\mathrm{G}$. It is found that the axial velocity enhances with increase in thermal buoyancy parameter $(G)$. From figs $(2 \& 3)$ we notice that the axial velocity depreciates with increase in the Hartman number $\mathrm{M}$ and enhances with Hall parameter (m). From fig.4 we find that lesser the molecular diffusivity smaller $\left|f^{1}(\eta)\right|$ in the flow region. With respect to buoyancy ratio $\mathrm{N}$ we find that when the molecular buoyancy force dominates over the thermal buoyancy force the magnitude of $f^{1}(\eta)$ enhances when the buoyancy forces act in the same direction and depreciates for the forces acting in opposite directions (fig.5). The variation of $f^{1}(\eta)$ with Eckert number Ec reveals that higher the dissipative heat larger $\left|f^{1}(\eta)\right|$ in the flow region (fig.6). An increase in the strength of the heat generating source reduces $\left|f^{1}(\eta)\right|$ (fig. 7). The variation of $f^{1}(\eta)$ with chemical reaction parameter $k$ shows that $\left|f^{1}(\eta)\right|$ depreciates in the degenerating chemical reaction case and enhances in the generating chemical reaction cases (fig.8). Also higher the radiation absorption parameter $\mathrm{Q}_{1}$ larger $\left|\mathrm{f}^{1}(\eta)\right|$ in the region (fig.9). From fig.10 we find that $\left|f^{1}(\eta)\right|$ enhances with increase in the Soret parameter $S_{0}$. An increase in the density ratio $\gamma$ enhances $\left|\mathrm{f}^{1}(\eta)\right|$ (fig. 11).

The transverse velocity $(f(\eta))$ is exhibited in figure 12 for different values of $G$. It is found that the transverse velocity experiences a depreciation with increase in $\mathrm{G} \leq 2 \times 10^{2}$ and enhances with higher $\mathrm{G} \geq$ $3 \times 10^{2}$. The variation of $\mathrm{f}$ with Hartmann number $\mathrm{M}$ shows that higher the Lorentz force lesser the transverse velocity (fig.13). An increase in the Hall parameter $\mathrm{m} \leq 1.5$ results in an enhancement in $\mathrm{f}(\eta)$ and reduces with higher $m=2$ and again enhances with still higher $\mathrm{m}=2.5$ (fig.14). With respect to Sc we find that lesser the molecular diffusivity smaller the transverse velocity (fig.15). When the molecular buoyancy force dominates over the thermal buoyancy force the transverse velocity enhances when the buoyancy forces act in the same direction while for the forces acting in opposite directions it depreciates in the flow region (fig.16). The variation of $\mathrm{f}$ with $\mathrm{Ec}$ is exhibited in fig. 17. It is observed that higher the dissipative heat larger the transverse velocity. $f(\eta)$ reduces with increase in $\alpha$ (fig.
18).With respect to chemical reaction parameter $\mathrm{k}$, we notice that the transverse velocity depreciates with $\mathrm{k}$ in the degenerating chemical reaction case and enhances in the generating chemical reaction case (fig.19). An increase in the radiation absorption parameter $Q_{1}$ results in an enhancement in $f(\eta)$ in the entire flow region (fig.20). An increase in $S_{0}$ enhances $|f(\eta)|$ (fig.21). From fig. 22 we notice an enhancement in $|f(\eta)|$ with density ratio $\gamma$.

The cross velocity $(g(\eta))$ is exhibited in figure 23 for different values of $G$. It is found that $|g|$ enhances with increase in $\mathrm{G}$ or $\mathrm{M}$ or $\mathrm{m}$ or $\mathrm{Ec}$ or $\mathrm{Q}_{1}$ (figs.23,24,25,28 \& 31). $|\mathrm{g}|$ reduces with increase in Sc (fig.26). $|\mathrm{g}|$ enhances with $\mathrm{N}>0$ and reduces with $|\mathrm{N}|$ (fig.27). $|\mathrm{g}|$ reduces with the strength of the heat source (fig. 29). $|\mathrm{g}|$ experiences a depreciation with increase in the chemical reaction parameter $\mathrm{k}$ in the degenerating chemical reaction case and enhances in the generating chemical reaction case (fig.30). An increase in $S_{0}$ or $\gamma$ enhances the $|\mathrm{g}(\eta)|$ (figs.32 \&33).

The non - dimensional temperature $(\theta)$ is shown in figure 34 for different values of $\mathrm{G}$. We follow the convention that the non - dimensional temperature is positive or negative according as the actual temperature $(\mathrm{T})$ is greater / lesser than Too. It is found that higher the thermal buoyancy parameter $G$ or Hall parameter (m) or Soret Parameter (figs.34, 36 \& 43) smaller the actual temperature. Higher the Lorentz force or lesser the molecular diffusivity larger the actual temperature (figs.35 \& 37). When the molecular buoyancy force dominates over the thermal buoyancy force the actual temperature depreciates when the buoyancy forces act in the same direction and for the forces acting in opposite directions, it enhances in the flow region (fig.38). The variation of $\theta$ with $\mathrm{Ec}$ is exhibited in fig.39. It is observed that higher the dissipative heat larger the actual temperature.The actual temperature reduces with $\alpha$ (fig.40). The actual temperature enhances with increase in the chemical reaction parameter $\mathrm{k}>0$ and reduces with $|\mathrm{k}| \quad(<0)$ (fig.41). The actual temperature enhances with increase in radiation absorption parameter $\mathrm{Q}_{1}$ in the entire flow region (fig. 42). From fig.44, the actual temperature reduces with $\gamma$.

The concentration distribution $(\phi)$ is shown in figure 45 for different values of $\mathrm{G}$. We follow the convention that the non - dimensional concentration is positive or negative according as the actual concentration is greater / lesser than $\mathrm{C} \infty$. An increase in $\mathrm{G}$ or $\mathrm{m}$ or $\mathrm{Sc}$ or $\mathrm{Ec}$ or $\mathrm{Q}_{1}$ leads to a depreciation in the actual concentration (figs.45,47,48, 50 \& 53). Higher the Lorentz force larger the actual concentration (fig.46). When the molecular buoyancy force dominates over the thermal buoyancy force the actual concentration depreciates when the buoyancy forces act in the same direction and for the forces acting in opposite directions it enhances in the flow region (fig.49). The actual concentration enhances with $\alpha$ (fig.51). The actual concentration reduces with $\mathrm{k}>0$ and enhances with $\mathrm{k}<0$ (fig.52). Higher the thermal diffusion effect larger the concentration in the flow 


\section{International Journal of Research in Advent Technology, Vol.7, No.4, April 2019 E-ISSN: 2321-9637 \\ Available online at www.ijrat.org}

region (fig.54). The actual concentration reduces with $\gamma$ (fig.55)

The stress component $\left(\tau_{\mathrm{x}}\right)$ is shown in tables 1 , $5 \& 9$ for different values. It is found that $\left|\tau_{\mathrm{x}}\right|$ at $\eta=0$ enhances with increase in $\mathrm{G}$ or $\mathrm{m}$ and reduces with $\mathrm{M}$. Lesser the molecular diffusivity smaller $\left|\tau_{\mathrm{x}}\right|$. It enhances with increase in the buoyancy ratio $\mathrm{N}>0$ and reduces with $|\mathrm{N}|(<0) \mid$ (table 1). $\mid \tau_{\mathrm{x}}$ |depreciates with increase in the chemical reaction parameter $\mathrm{k}>0$ and enhances in the generating case $(\mathrm{k}<0)$ and enhances with $\mathrm{Q}_{1} \cdot\left|\tau_{\mathrm{x}}\right|$ reduces with increase in the strength of the heat generating source and enhances with that of heat absorbing source. An increase in Ec or $\mathrm{S}_{0}$ or $\gamma$ leads to an enhancement in $\left|\tau_{\mathrm{x}}\right|$

The stress component $\left(\tau_{\mathrm{z}}\right)$ at $\eta=0$ is shown in tables $2,6 \& 10$ for different values. $\left|\tau_{\mathrm{z}}\right|$ enhances with increase in $\mathrm{G}$ or $\mathrm{Q}_{1}$ or $\mathrm{m}$ or Ec or $\gamma$. An increase in Sc or heat source parameter $|\alpha|$ leads to a depreciation in $\left|\tau_{\mathrm{z}}\right|$. It reduces with increase in the chemical reaction parameter $\mathrm{k}>0$ and enhances with $\mathrm{k}<0$. $\left|\tau_{\mathrm{z}}\right|$ enhances with buoyancy ratio $\mathrm{N}>0$ and reduces with $|\mathrm{N}|(<0)$ and also it enhances with $\mathrm{S}_{0}$ or $\gamma$.

The rate of heat transfer (Nusselt number) at $\eta$ $=0$ is depicted in tables $3,7 \& 11$. The rate of heat transfer enhances with increase in $G$ or heat source parameter $\alpha$ or Hall parameter $\mathrm{m}$. $|\mathrm{Nu}|$ reduces with $\mathrm{M}$ or $\mathrm{Q}_{1}$ or $\mathrm{Ec}$ or $\mathrm{S}_{0}$. With respect to buoyancy ratio $\mathrm{N}$ we find that $|\mathrm{Nu}|$ enhances with $\mathrm{N}>0$ and reduces with $|\mathrm{N}|$ $(<0)$. Also $|\mathrm{Nu}|$ depreciates in the degenerating chemical reaction case and enhances in the generating chemical reaction case. An increase in the density ratio $\gamma$ leads to an enhancement in $|\mathrm{Nu}|$ at $\eta=0$.

The rate of mass transfer (Sherwood number) at $\eta=0$ is shown in tables $4,8 \& 12$ for different variations. It is found that higher the thermal buoyancy parameter $\mathrm{G}$ or Hall parameter $\mathrm{m}$ or lesser the molecular diffusivity larger $|\mathrm{Sh}|$ at $\eta=0$. With respect to $\mathrm{N}$, we find that $|\mathrm{Sh}|$ enhances with $\mathrm{N}>0$ when the buoyancy forces act in the same direction and depreciates with $|\mathrm{N}|(<0)$ when they act in opposite directions. Higher the Lorentz force lesser $|\mathrm{Sh}|$ at $\eta=0$. $|\mathrm{Sh}|$ experiences an enhancement in both degenerating and generating chemical reaction cases. Also it enhances with radiation absorption parameter $\mathrm{Q}_{1}$ or $\mathrm{Ec}$ or $\gamma .|\mathrm{Sh}|$ reduces with increase in the strength of the heat generating source or enhances with that of heat absorbing source. $|\mathrm{Sh}|$ reduces with $\mathrm{S}_{0} \leq 1.5$ and enhances with $S_{0} \geq 2.5$. The variation of Sh with density ratio $\gamma$ shows that the non-linearity in the density temperature relation enhances $|\mathrm{Sh}|$ at $\eta=0$.

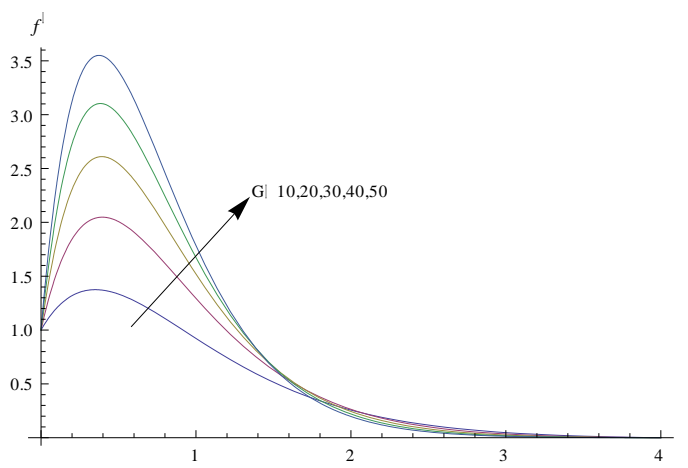

Fig. 1 : Variation of $\mathrm{f}^{1}$ with $\mathrm{G}$

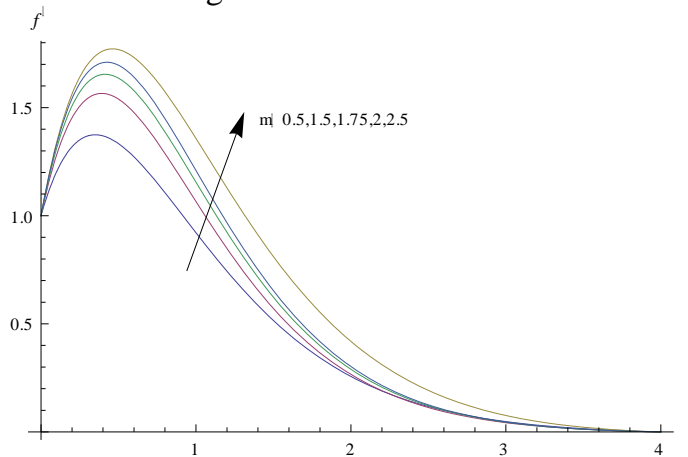

Fig. 3 : Variation of $\mathrm{f}^{1}$ with $\mathrm{m}$

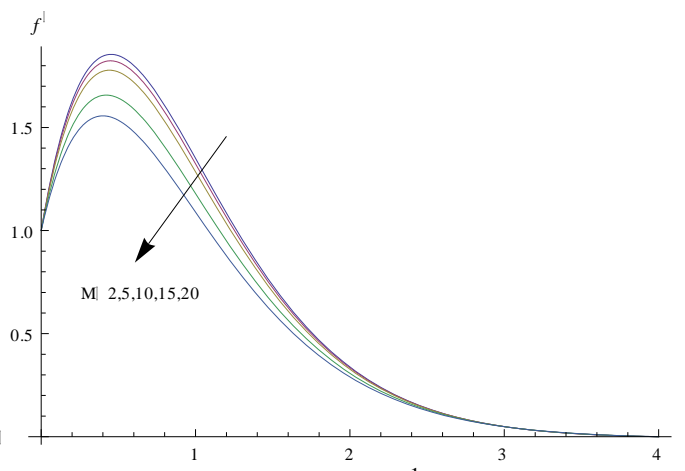

Fig. 2 : Variation of $\mathrm{f}^{1}$ with $\mathrm{M}$

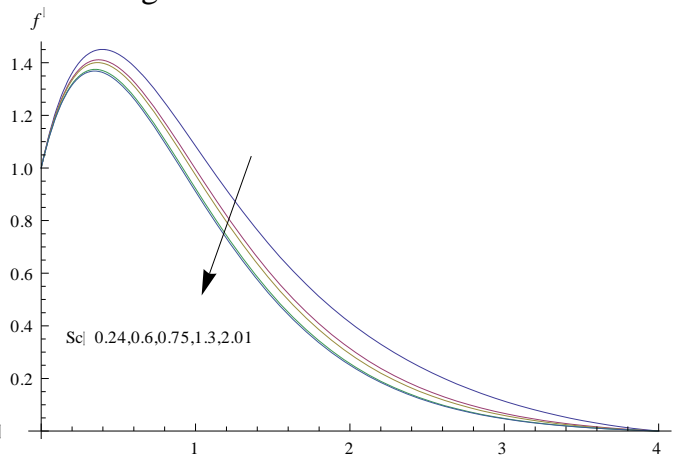

Fig. 4 : Variation of $\mathrm{f}^{1}$ with Sc 
Available online at www.ijrat.org

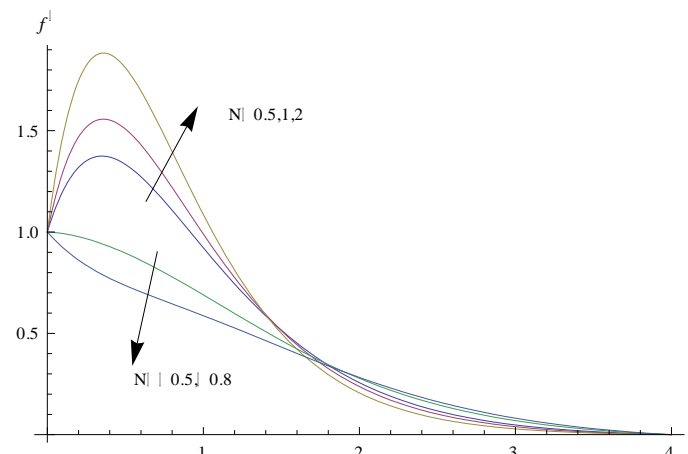

Fig. 5 : Variation of $\mathrm{f}^{1}$ with $\mathrm{N}$

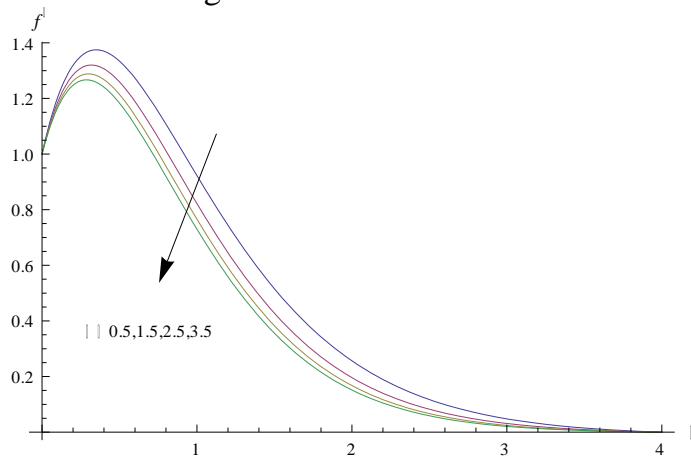

Fig. 7 : Variation of $\mathrm{f}^{1}$ with $\alpha$

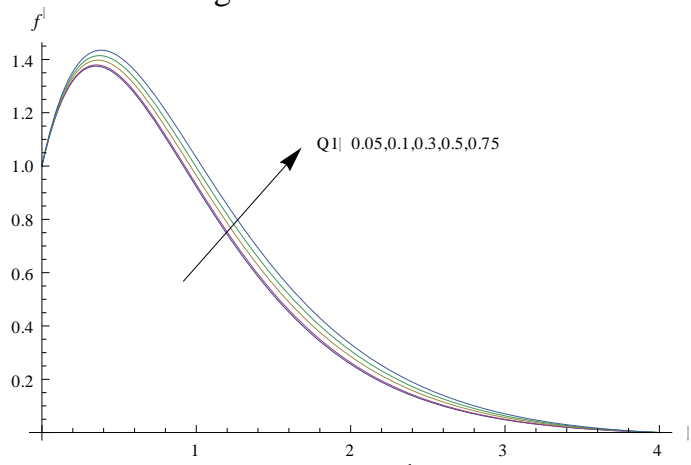

Fig. 9 : Variation of $\mathrm{f}^{1}$ with $\mathrm{Q}_{1}$

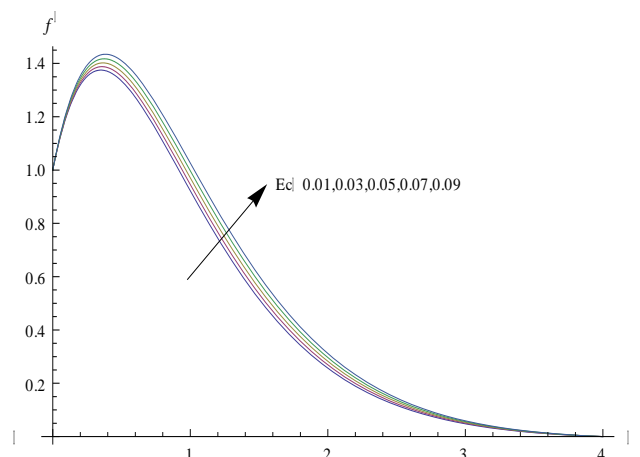

Fig. 6 : Variation of $\mathrm{f}^{1}$ with Ec

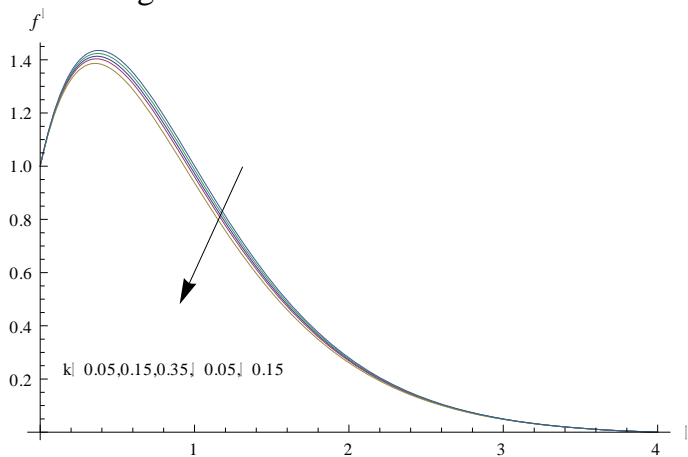

Fig. 8 : Variation of $\mathrm{f}^{1}$ with $\mathrm{k}$

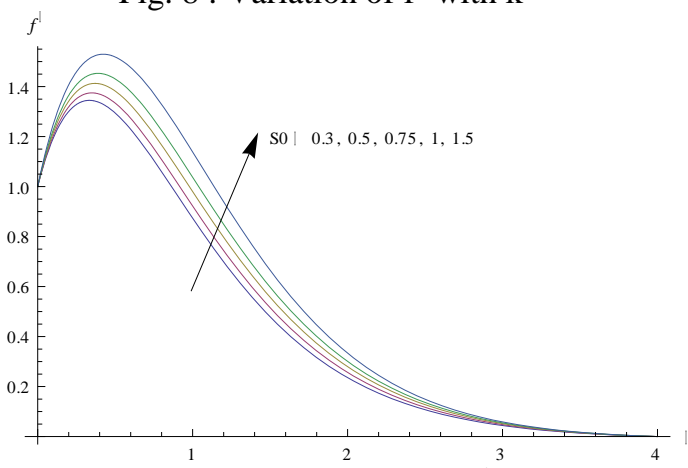

Fig. 10 : Variation of $f^{1}$ with $S_{0}$

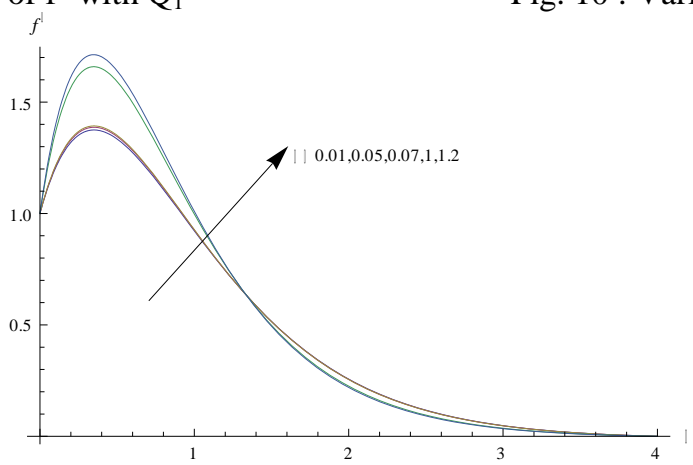

Fig. 11 : Variation of $f^{1}$ with $\gamma$ 
Available online at www.ijrat.org

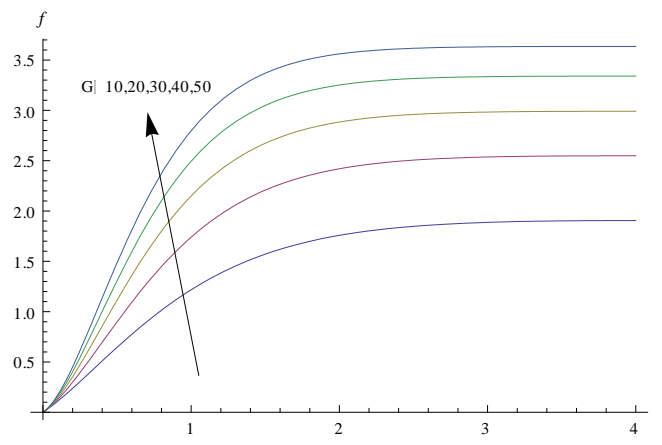

Fig.12 : Variation of $f$ with $G$

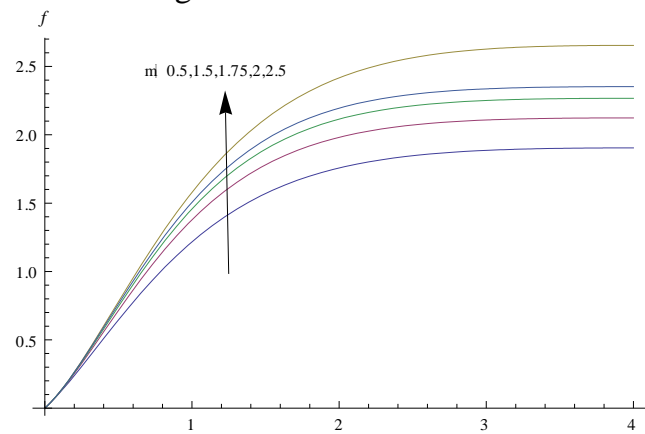

Fig. 14 : Variation of $\mathrm{f}$ with $\mathrm{m}$

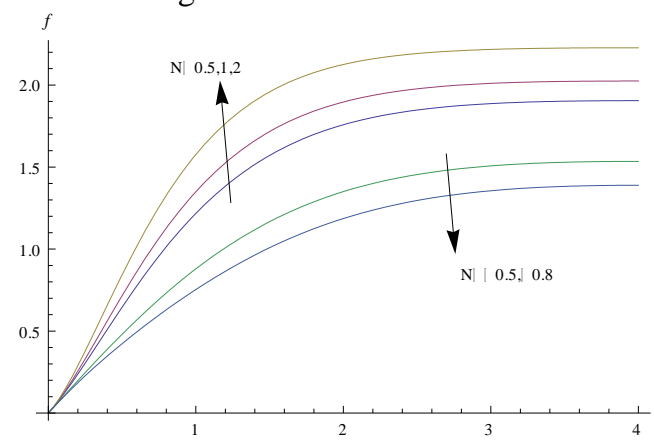

Fig.16 : Variation of $\mathrm{f}$ with $\mathrm{N}$

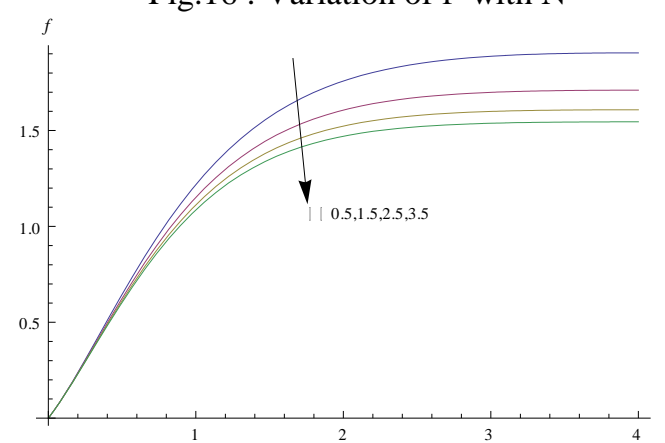

Fig. 18 : Variation of $f$ with $\alpha$

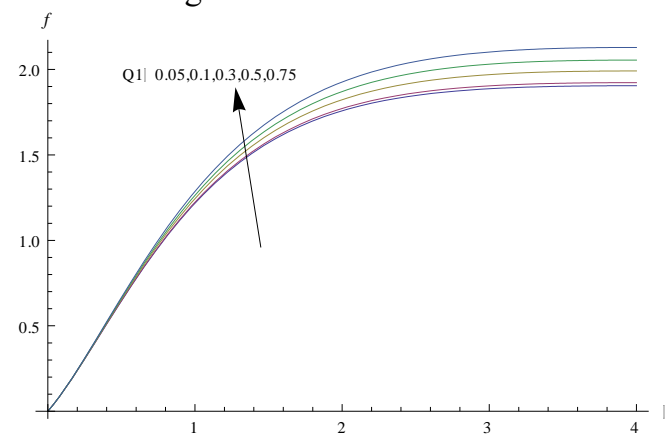

Fig.20 : Variation of $\mathrm{f}$ with $\mathrm{Q}_{1}$

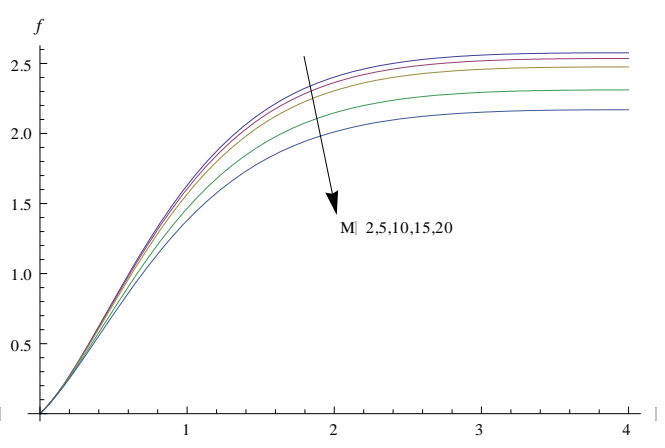

Fig.13 : Variation of $\mathrm{f}$ with $\mathrm{M}$

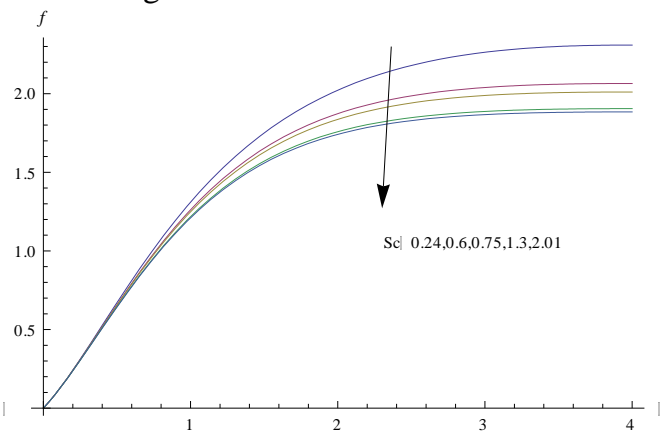

Fig. 15 : Variation of $\mathrm{f}$ with Sc

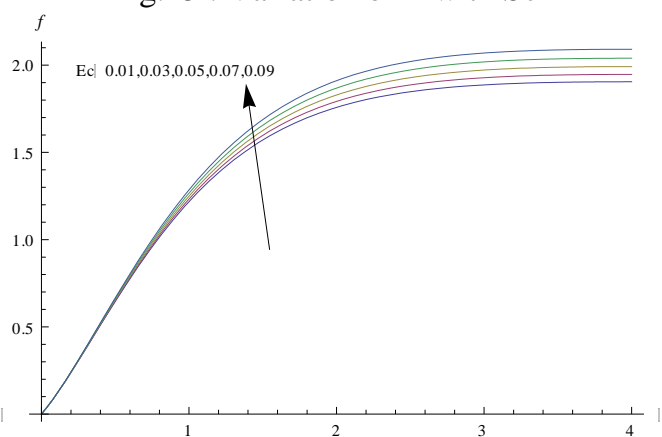

Fig. 17 : Variation of $f$ with Ec

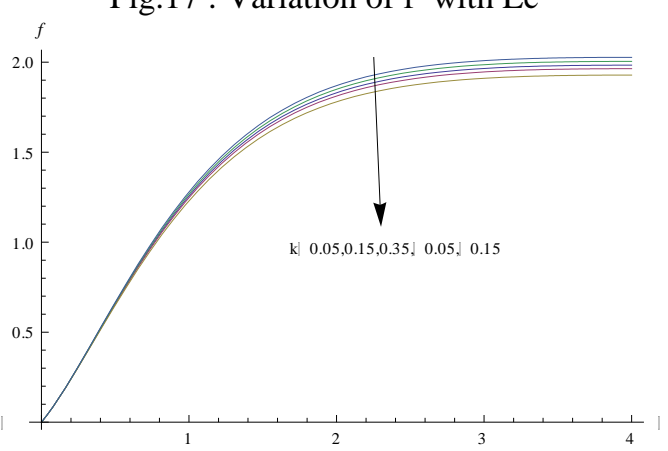

Fig.19 : Variation of $\mathrm{f}$ with $\mathrm{k}$

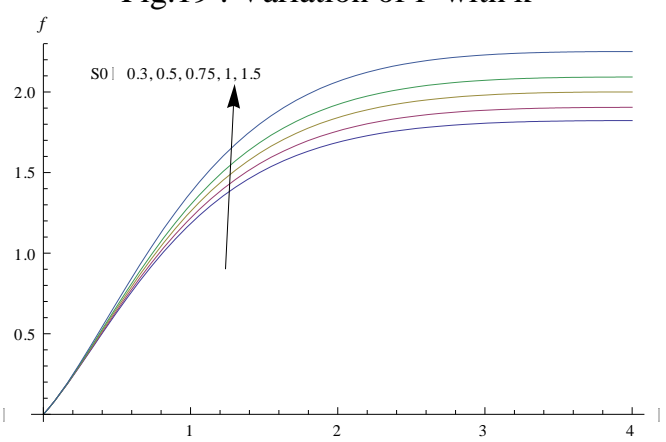

Fig.21 : Variation of $\mathrm{f}$ with $\mathrm{S}_{0}$ 
Available online at www.ijrat.org

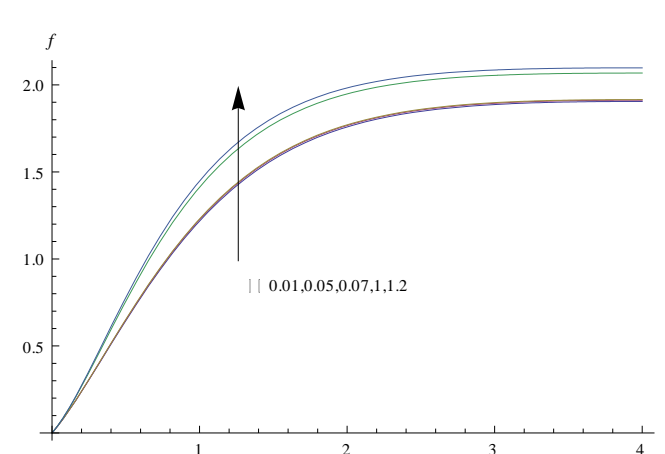

Fig.22 : Variation of $f$ with $\gamma$

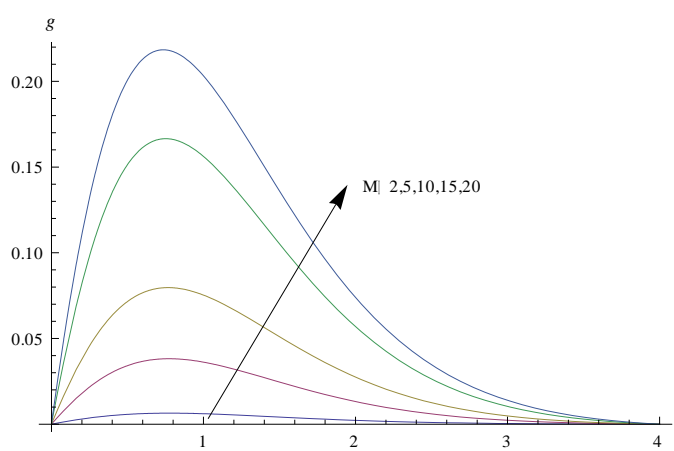

Fig.24 : Variation of g with $\mathrm{M}$

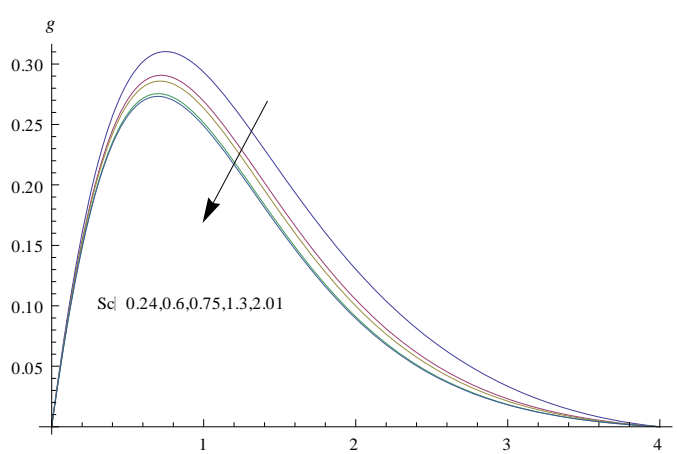

Fig.26 : Variation of g with Sc

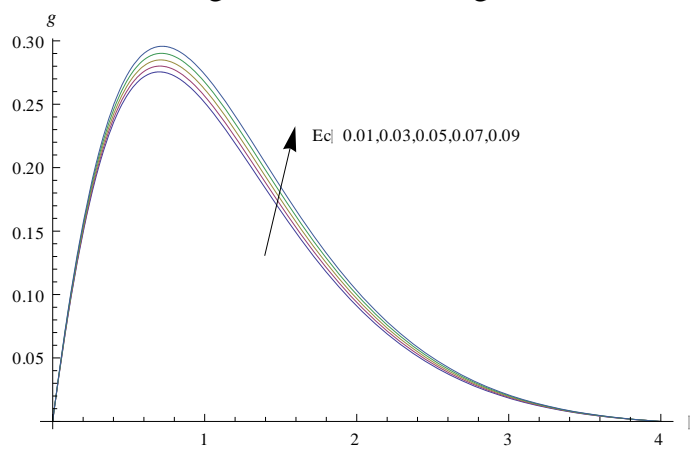

Fig.28 : Variation of $\mathrm{g}$ with Ec

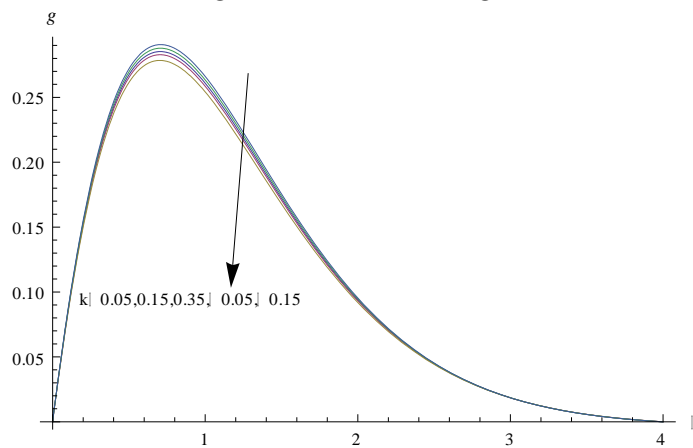

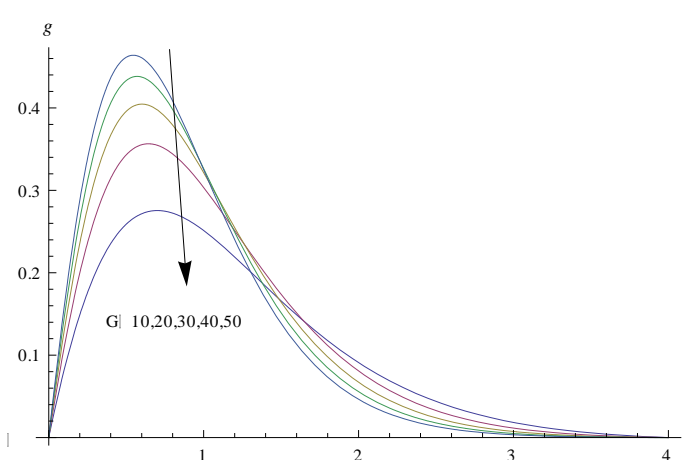

Fig. 23 : Variation of $\mathrm{g}$ with $\mathrm{G}$

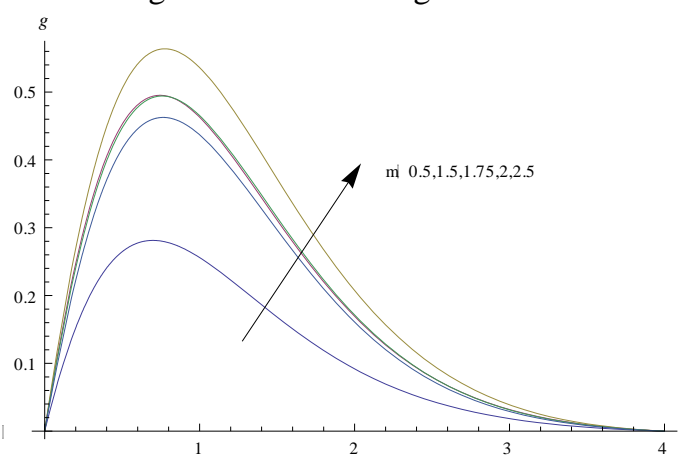

Fig. 25 : Variation of $\mathrm{g}$ with $\mathrm{m}$

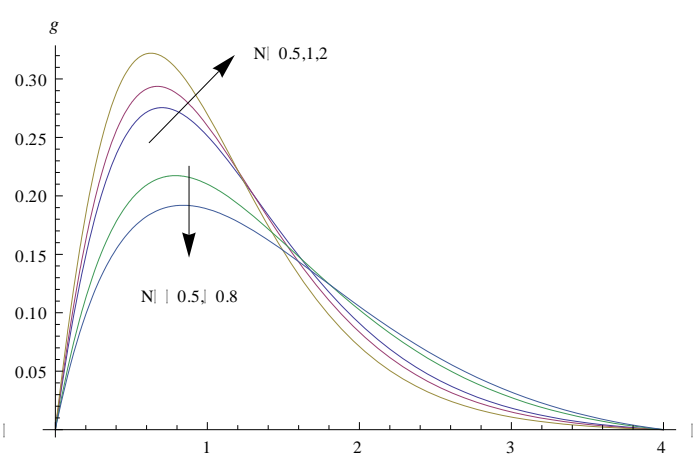

Fig. 27 : Variation of g with $\mathrm{N}$

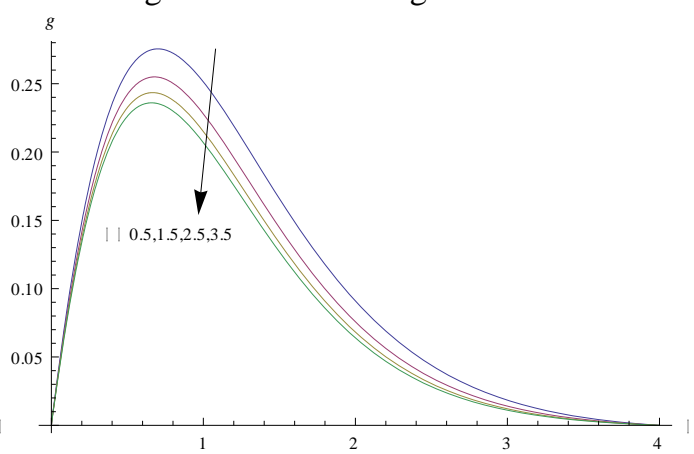

Fig.29 : Variation of $\mathrm{g}$ with $\alpha$

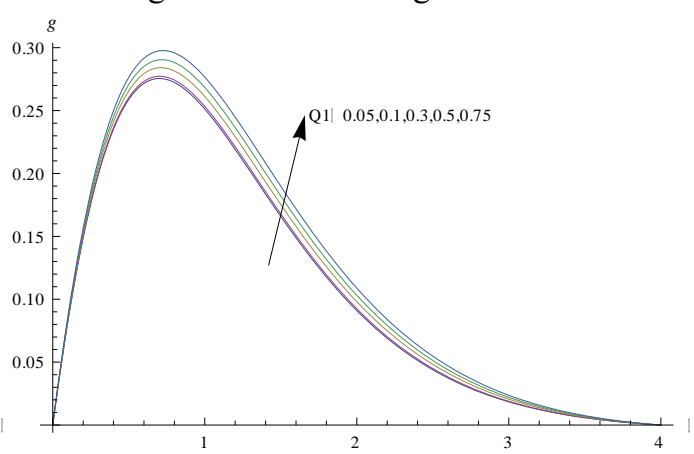


Available online at www.ijrat.org

Fig.30 : Variation of $\mathrm{g}$ with $\mathrm{k}$

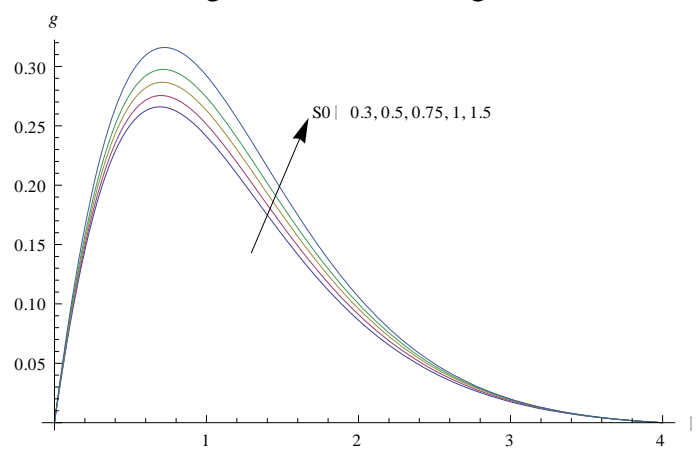

Fig.32 : Variation of $g$ with $\mathrm{S}_{0}$

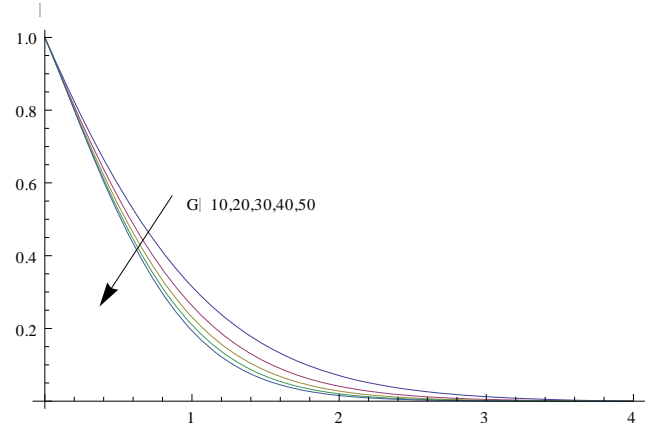

Fig.34 : Variation of $\theta$ with $\mathrm{G}$

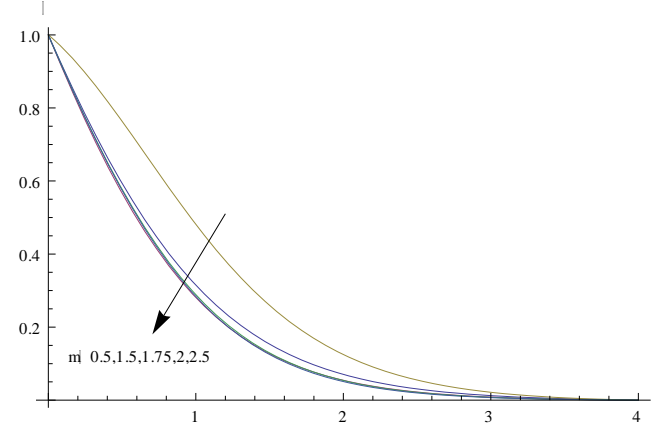

Fig.36 : Variation of $\theta$ with $\mathrm{m}$

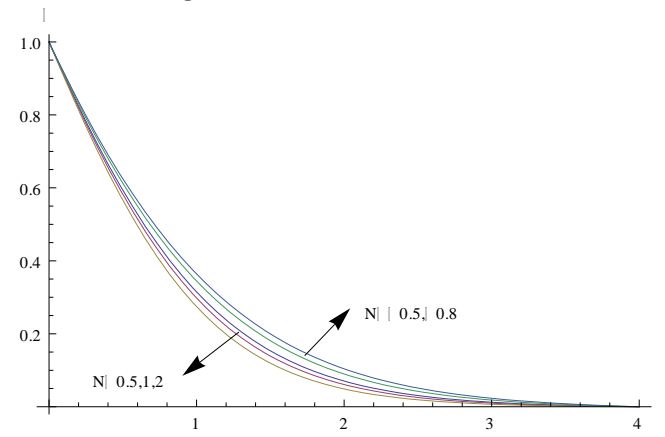

Fig.38 : Variation of $\theta$ with $\mathrm{N}$

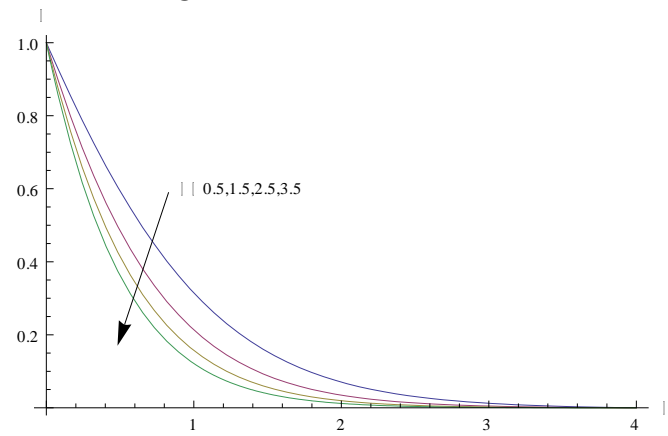

Fig.31 : Variation of g with $\mathrm{Q}_{1}$

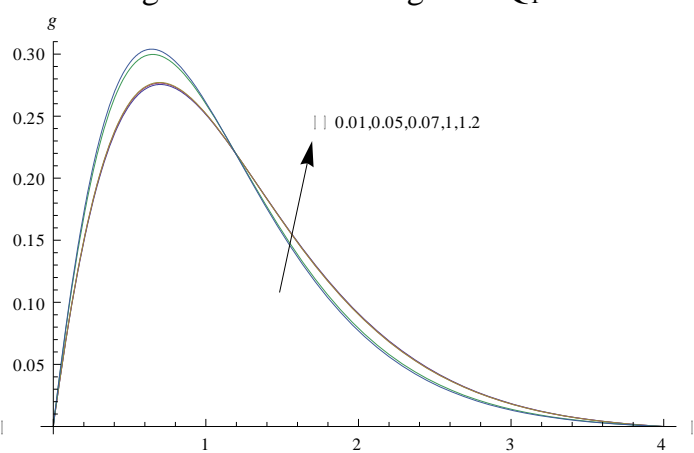

Fig.33 : Variation of g with $\gamma$

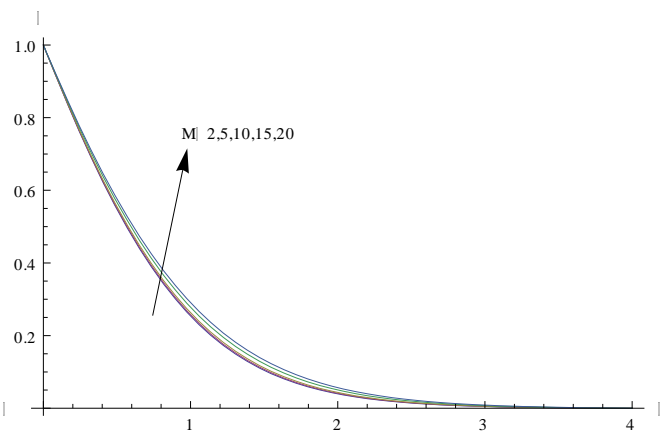

Fig. 35 : Variation of $\theta$ with $\mathrm{M}$

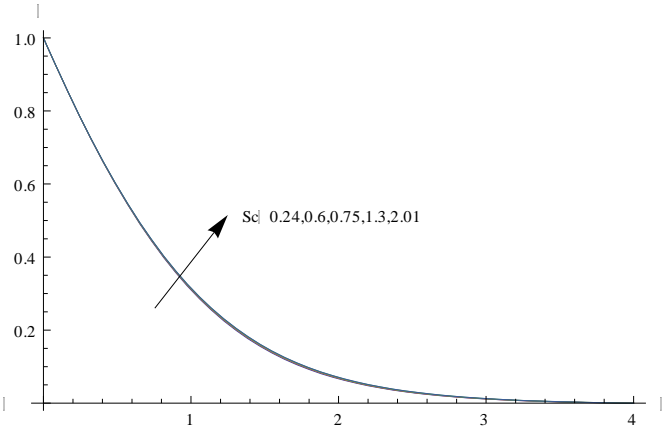

Fig.37 : Variation of $\theta$ with Sc

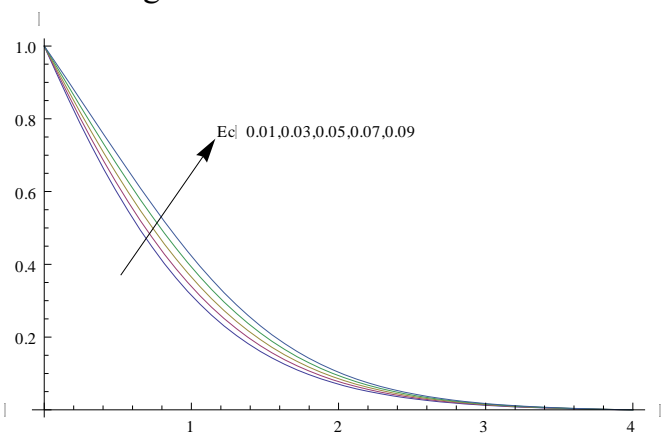

Fig.39 : Variation of $\theta$ with Ec

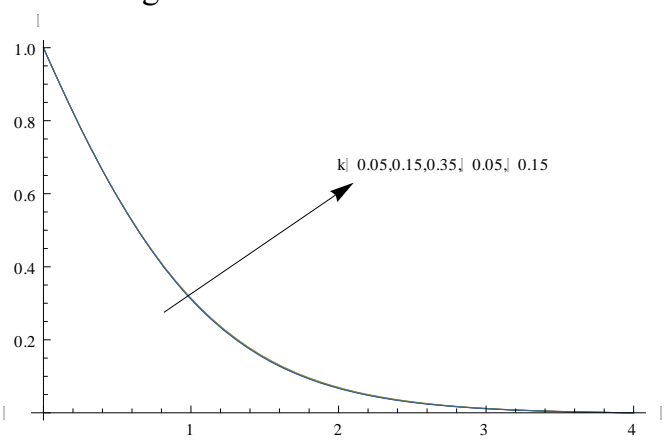


Available online at www.ijrat.org

Fig. 40 : Variation of $\theta$ with $\alpha$

Fig.41 : Variation of $\theta$ with $\mathrm{k}$

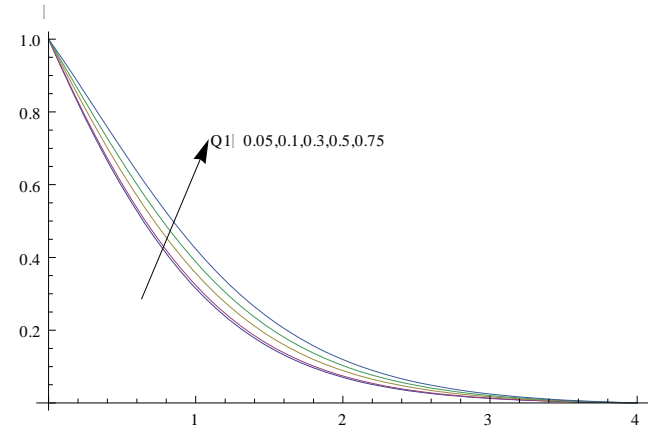

Fig.42 : Variation of $\theta$ with $\mathrm{Q}_{1}$

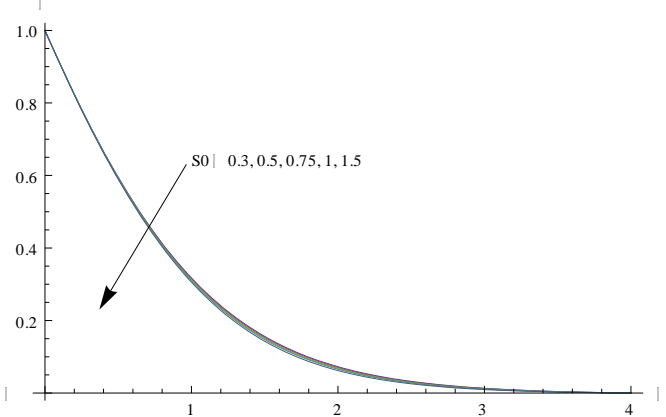

Fig.43 : Variation of $\theta$ with $\mathrm{S}_{0}$

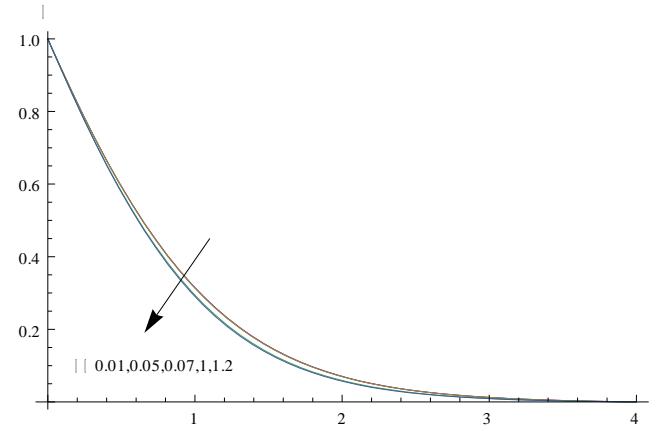

Fig.44 : Variation of $\theta$ with $\gamma$

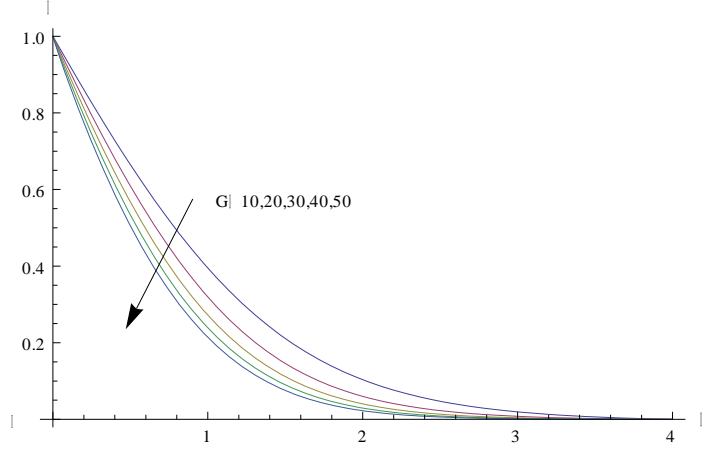

Fig.45 : Variation of $\phi$ with $\mathrm{G}$

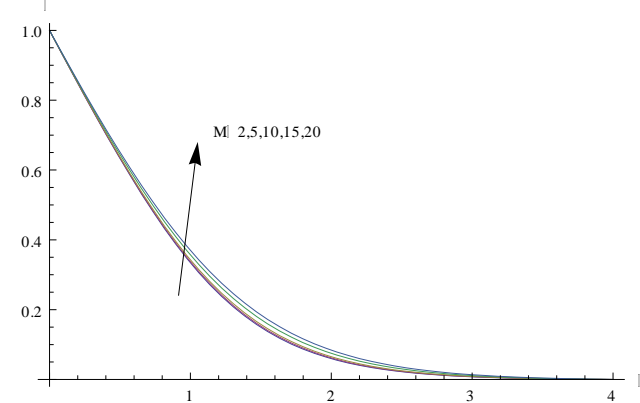

Fig.46 : Variation of $\phi$ with M

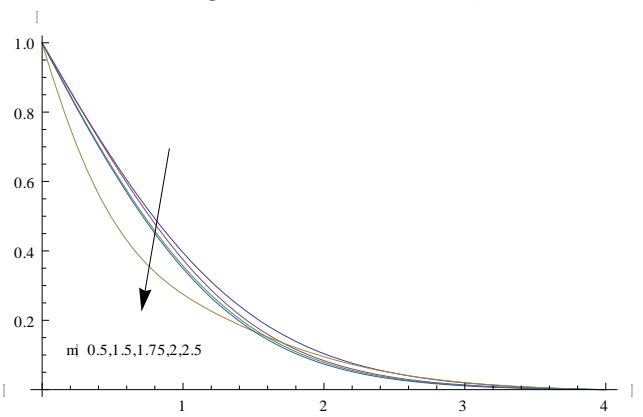

Fig.47 : Variation of $\phi$ with $\mathrm{m}$

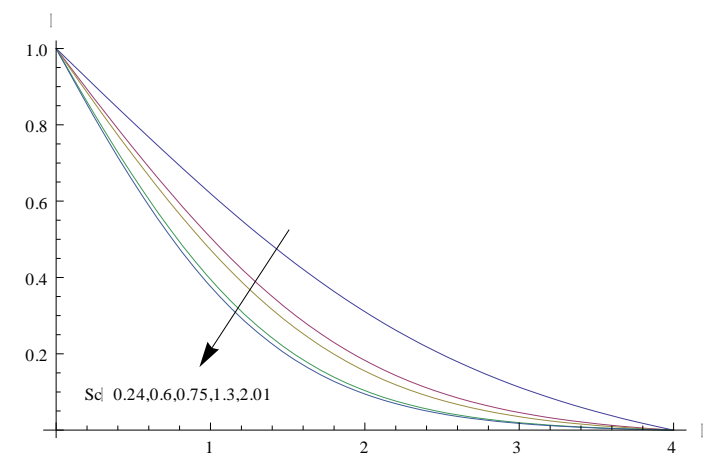

Fig.48 : Variation of $\phi$ with Sc

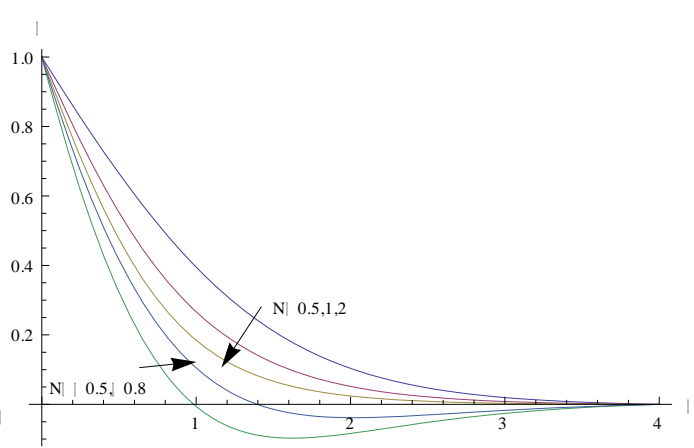

Fig.49 : Variation of $\phi$ with $\mathrm{N}$
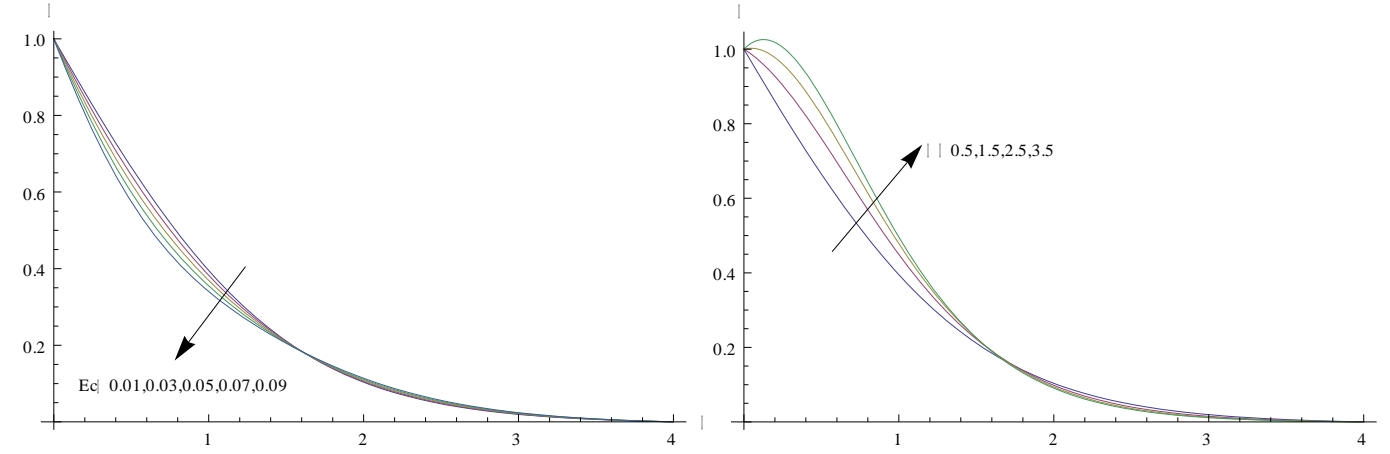
International Journal of Research in Advent Technology, Vol.7, No.4, April 2019

E-ISSN: 2321-9637

Available online at www.ijrat.org

Fig.50 : Variation of $\phi$ with Ec

Fig.51 : Variation of $\phi$ with $\alpha$

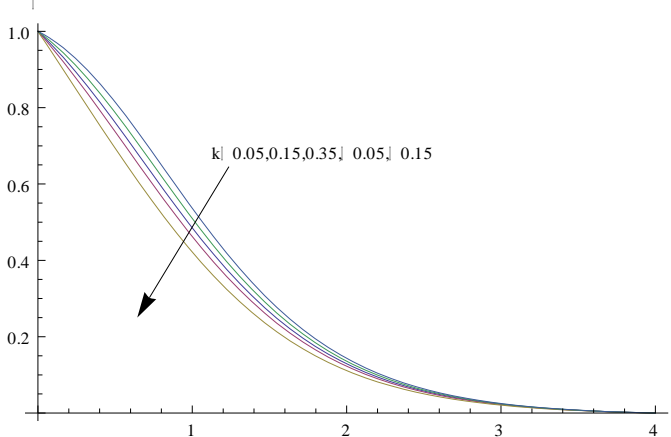

Fig.52 : Variation of $\phi$ with $\mathrm{k}$

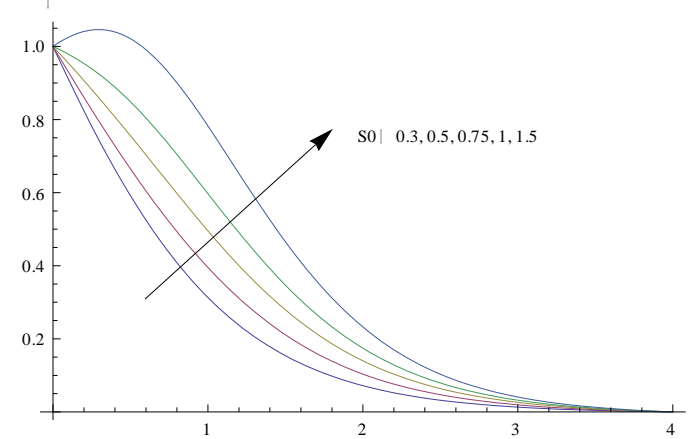

Fig.54 : Variation of $\phi$ with $\mathrm{S}_{0}$

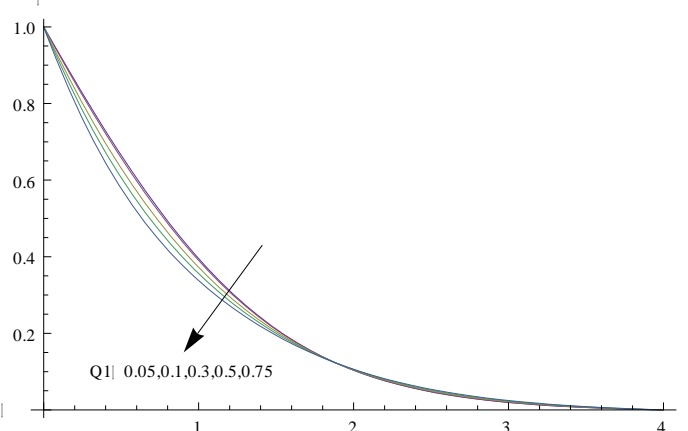

Fig.53 : Variation of $\phi$ with $\mathrm{Q}_{1}$

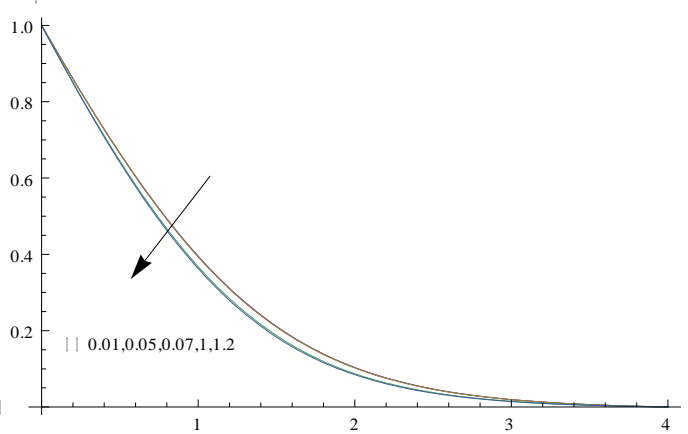

Fig.55 : Variation of $\phi$ with $\gamma$

Shit-2-stress $\tau_{\mathrm{x}}$ (TABLE 1)

\begin{tabular}{|c|c|c|c|c|c|c|c|c|}
\hline $\mathrm{M}$ & $\mathrm{I}$ & $\mathrm{II}$ & $\mathrm{III}$ & IV & V & VI & VII & VIII \\
\hline 1 & 4.42984 & 12.4133 & 6.86159 & 1.69482 & 0.792816 & 4.43329 & 4.80657 & 4.59493 \\
\hline 3 & 4.41336 & 12.3945 & 6.84447 & 1.67907 & 0.777271 & 4.42711 & 4.78875 & 4.57801 \\
\hline 5 & 4.38594 & 12.363 & 6.81598 & 1.65289 & 0.751426 & 4.41674 & 4.7591 & 4.54984 \\
\hline $\mathrm{G}$ & 10 & 30 & 10 & 10 & 10 & 10 & 10 & 10 \\
\hline $\mathrm{N}$ & $0.5(\mathrm{Sc}=1.3)$ & 0.5 & 1.5 & -0.5 & -0.8 & $\mathrm{~m}=1.5$ & $\mathrm{Sc}=0.22$ & 0.6 \\
\hline
\end{tabular}

\begin{tabular}{|c|c|c|c|c|c|c|c|c|}
\hline $\mathrm{M}$ & $\mathrm{I}$ & $\mathrm{II}$ & $\mathrm{III}$ & $\mathrm{IV}$ & $\mathrm{V}$ & $\mathrm{VI}$ & VII & VIII \\
\hline 1 & 0.00429032 & 0.00536462 & 0.00458438 & 0.00385731 & 0.00368823 & 0.00495647 & 0.0046321 & 0.00441349 \\
\hline 3 & 0.0170594 & 0.0213798 & 0.0182439 & 0.0153139 & 0.0146313 & 0.0197809 & 0.0184219 & 0.0175518 \\
\hline 5 & 0.0380067 & 0.047812 & 0.0407015 & 0.03403 & 0.0324715 & 0.0443388 & 0.0410541 & 0.0391127 \\
\hline $\mathrm{G}$ & 10 & 30 & 10 & 10 & 10 & 10 & 10 & 10 \\
\hline $\mathrm{N}$ & $0.5(\mathrm{Sc}=1.3)$ & 0.5 & 1.5 & -0.5 & -0.8 & $\mathrm{~m}=1.5$ & $\mathrm{Sc}=0.22$ & 0.6 \\
\hline
\end{tabular}

$\mathrm{Nu}$ (TABLE 3)

\begin{tabular}{|c|c|c|c|c|c|c|c|c|}
\hline $\mathrm{M}$ & $\mathrm{I}$ & $\mathrm{II}$ & $\mathrm{III}$ & $\mathrm{IV}$ & $\mathrm{V}$ & $\mathrm{VI}$ & $\mathrm{VII}$ & $\mathrm{VIII}$ \\
\hline 1 & 1.02339 & 1.09283 & 1.05588 & 0.987808 & 0.96247 & 1.0235 & 1.0381 & 1.0293 \\
\hline 3 & 1.02244 & 1.09178 & 1.05494 & 0.986854 & 0.96149 & 1.02289 & 1.03704 & 1.02832 \\
\hline 5 & 1.02088 & 1.09003 & 1.05338 & 0.985271 & 0.95986 & 1.02186 & 1.03528 & 1.02669 \\
\hline $\mathrm{G}$ & 10 & 30 & 10 & 10 & 10 & 10 & 10 & 10 \\
\hline $\mathrm{N}$ & $0.5(\mathrm{Sc}=1.3)$ & 0.5 & 1.5 & -0.5 & -0.8 & $\mathrm{~m}=1.5$ & $\mathrm{Sc}=0.22$ & 0.6 \\
\hline
\end{tabular}

Sh (TABLE 4)

\begin{tabular}{|c|c|c|c|c|c|c|c|c|}
\hline $\mathrm{M}$ & $\mathrm{I}$ & $\mathrm{II}$ & $\mathrm{III}$ & $\mathrm{IV}$ & $\mathrm{V}$ & $\mathrm{VI}$ & $\mathrm{VII}$ & $\mathrm{VIII}$ \\
\hline 1 & 0.77875 & 1.05503 & 1.23885 & 1.85249 & 1.58967 & 0.778929 & 0.416396 & 0.593274 \\
\hline 3 & 0.778278 & 1.05485 & 1.23818 & 1.85112 & 1.58837 & 0.778994 & 0.416145 & 0.59287 \\
\hline 5 & 0.777487 & 1.05454 & 1.23706 & 1.84883 & 1.58621 & 0.779093 & 0.415725 & 0.592194 \\
\hline $\mathrm{G}$ & 10 & 30 & 10 & 10 & 10 & 10 & 10 & 10 \\
\hline $\mathrm{N}$ & $0.5(\mathrm{Sc}=1.3)$ & 0.5 & 1.5 & -0.5 & -0.8 & $\mathrm{~m}=1.5$ & $\mathrm{Sc}=0.22$ & 0.6 \\
\hline
\end{tabular}


International Journal of Research in Advent Technology, Vol.7, No.4, April 2019

E-ISSN: 2321-9637

Available online at www.ijrat.org

\begin{tabular}{|c|c|c|c|c|c|c|c|c|c|}
\hline \multicolumn{10}{|c|}{$\tau_{\mathrm{x}}(\mathrm{TABLE} 5)$} \\
\hline $\mathrm{M}$ & $\mathrm{I}$ & II & III & IV & $\mathrm{V}$ & VI & VII & VIII & IX \\
\hline 1 & 4.42984 & 4.21331 & 4.06834 & 4.80561 & 5.71896 & 4.23541 & 4.10028 & 4.73696 & 5.27173 \\
\hline 3 & 4.41336 & 4.19697 & 4.05218 & 4.78933 & 5.69989 & 4.21889 & 4.08382 & 4.72083 & 5.25682 \\
\hline 5 & 4.38594 & 4.1698 & 4.0253 & 4.76225 & 5.66844 & 4.19142 & 4.05644 & 4.6942 & 5.23208 \\
\hline$\alpha$ & 0.5 & 1.5 & 2.5 & -0.5 & -1.5 & 0.5 & 0.5 & 0.5 & 0.5 \\
\hline$\gamma$ & 0.5 & 0.5 & 0.5 & 0.5 & 0.5 & 1.5 & 2.5 & -0.5 & -1.5 \\
\hline
\end{tabular}

$\tau_{\mathrm{z}}$ (TABLE 6)

\begin{tabular}{|c|c|c|c|c|c|c|c|c|c|}
\hline$M$ & I & II & III & IV & $\mathrm{V}$ & $\mathrm{VI}$ & VII & VIII & IX \\
\hline 1 & $\begin{array}{c}0.0042903 \\
2 \\
\end{array}$ & $\begin{array}{c}0.0041602 \\
8\end{array}$ & $\begin{array}{c}0.0040771 \\
1\end{array}$ & $\begin{array}{c}0.0045118 \\
4\end{array}$ & $\begin{array}{c}0.0034611 \\
2\end{array}$ & $\begin{array}{c}0.0042213 \\
5\end{array}$ & $\begin{array}{c}0.0041743 \\
1\end{array}$ & $\begin{array}{c}0.00439 \\
8\end{array}$ & $\begin{array}{c}0.0045718 \\
3 \\
\end{array}$ \\
\hline 3 & 0.0170594 & 0.0165376 & 0.016204 & 0.0179494 & 0.0139325 & 0.0167813 & 0.0165917 & $\begin{array}{c}0.01749 \\
4 \\
\end{array}$ & 0.0181961 \\
\hline 5 & 0.0380067 & 0.036827 & 0.0360731 & 0.0400228 & 0.0316332 & 0.0373727 & 0.036941 & 0.03899 & 0.0406032 \\
\hline$\alpha$ & 0.5 & 1.5 & 2.5 & -0.5 & -1.5 & 0.5 & 0.5 & 0.5 & 0.5 \\
\hline$\gamma$ & 0.5 & 0.5 & 0.5 & 0.5 & 0.5 & 1.5 & 2.5 & -0.5 & -1.5 \\
\hline
\end{tabular}

$\mathrm{Nu}(\mathrm{TABLE} 7)$

\begin{tabular}{|c|c|c|c|c|c|c|c|c|c|}
\hline $\mathrm{M}$ & $\mathrm{I}$ & $\mathrm{II}$ & $\mathrm{III}$ & $\mathrm{IV}$ & $\mathrm{V}$ & $\mathrm{VI}$ & $\mathrm{VII}$ & $\mathrm{VIII}$ & $\mathrm{IX}$ \\
\hline 1 & 1.02339 & 1.40471 & 1.71219 & 0.488646 & -1.17998 & 1.01972 & 1.01718 & 1.02884 & 1.03647 \\
\hline 3 & 1.02244 & 1.40409 & 1.71173 & 0.486794 & -1.1797 & 1.01878 & 1.01625 & 1.02789 & 1.03551 \\
\hline 5 & 1.02088 & 1.40307 & 1.71097 & 0.483708 & -1.17954 & 1.01722 & 1.0147 & 1.02631 & 1.03391 \\
\hline$\alpha$ & 0.5 & 1.5 & 2.5 & -0.5 & -1.5 & 0.5 & 0.5 & 0.5 & 0.5 \\
\hline$\gamma$ & 0.5 & 0.5 & 0.5 & 0.5 & 0.5 & 1.5 & 2.5 & -0.5 & -1.5 \\
\hline
\end{tabular}

Sh (TABLE 8)

\begin{tabular}{|c|c|c|c|c|c|c|c|c|c|}
\hline $\mathrm{M}$ & I & II & III & IV & V & VI & VII & VIII & IX \\
\hline 1 & 0.77875 & 0.362969 & 0.017562 & 1.33188 & 2.86894 & 1.28765 & 1.6883 & 0.0641607 & -1.09204 \\
\hline 3 & 0.778278 & 0.362129 & 0.0165221 & 1.33229 & 2.86912 & 1.28751 & 1.68827 & 0.0627046 & -1.09651 \\
\hline 5 & 0.777487 & 0.360727 & 0.0147862 & 1.33297 & 2.86928 & 1.28726 & 1.68823 & 0.0602646 & -1.104123 \\
\hline$\alpha$ & 0.5 & 1.5 & 2.5 & -0.5 & -1.5 & 0.5 & 0.5 & 0.5 & 0.5 \\
\hline$\gamma$ & 0.5 & 0.5 & 0.5 & 0.5 & 0.5 & 1.5 & 2.5 & -0.5 & -1.5 \\
\hline
\end{tabular}

$\tau_{\mathrm{x}}($ TABLE 9)

\begin{tabular}{|l|l|l|l|l|l|l|l|l|l|}
\hline $\mathrm{M}$ & \multicolumn{1}{|c|}{ I } & \multicolumn{1}{|c|}{ II } & \multicolumn{1}{c|}{ III } & \multicolumn{1}{|c|}{ IV } & \multicolumn{1}{c|}{ V } & \multicolumn{1}{c|}{ VI } & \multicolumn{1}{c|}{ VII } & \multicolumn{1}{c|}{ VIII } & \multicolumn{1}{c|}{ IX } \\
\hline 1 & 4.42984 & 4.46307 & 4.52686 & 4.46714 & 4.48601 & 5.04772 & 5.60922 & 4.47345 & 4.517 \\
\hline 3 & 4.41336 & 4.44657 & 4.51031 & 4.45167 & 4.47109 & 5.03004 & 5.59044 & 4.45697 & 4.5002 \\
\hline 5 & 4.38594 & 4.41912 & 4.48277 & 4.42591 & 4.44621 & 5.0006 & 5.5592 & 4.42956 & 4.47311 \\
\hline Q1 & 0.05 & 0.15 & 0.3 & 0.05 & 0.05 & & & & \\
\hline Ec & 0.01 & 0.01 & 0.01 & 0.05 & 0.07 & So=1.5 & 2.5 & Gm=0.03 & 0.05 \\
\hline
\end{tabular}

$\tau_{\mathrm{z}}(\mathrm{TABLE} 10)$

\begin{tabular}{|c|c|c|c|c|c|c|c|c|c|}
\hline $\mathrm{M}$ & $\mathrm{I}$ & II & III & IV & $\mathrm{V}$ & VI & VII & VIII & IX \\
\hline 1 & $\begin{array}{c}0.004290 \\
3\end{array}$ & $\begin{array}{c}0.0043115 \\
6\end{array}$ & $\begin{array}{c}0.004351 \\
6\end{array}$ & $\begin{array}{c}0.0043172 \\
3\end{array}$ & $\begin{array}{c}0.0043305 \\
9\end{array}$ & $\begin{array}{c}0.0045363 \\
5\end{array}$ & $\begin{array}{c}0.0047226 \\
5\end{array}$ & $\begin{array}{c}0.0042953 \\
8\end{array}$ & $\begin{array}{c}0.0043004 \\
2\end{array}$ \\
\hline 3 & $\begin{array}{c}0.017059 \\
4 \\
\end{array}$ & 0.0171447 & $\begin{array}{c}0.017305 \\
2 \\
\end{array}$ & 0.0171694 & 0.0172241 & 0.0180484 & 0.0187974 & 0.0170798 & 0.0171001 \\
\hline 5 & $\begin{array}{c}0.038006 \\
7\end{array}$ & 0.0381992 & 0.038562 & 0.0382629 & 0.0383905 & 0.0402491 & 0.0419478 & 0.0380531 & 0.0380993 \\
\hline $\begin{array}{l}\mathrm{Q} \\
1\end{array}$ & 0.05 & 0.15 & 0.3 & 0.05 & 0.05 & & & & \\
\hline $\mathrm{Ec}$ & 0.01 & 0.01 & 0.01 & 0.05 & 0.07 & $\mathrm{So}=1.5$ & 2.5 & Gm0.03 & 0.05 \\
\hline
\end{tabular}


International Journal of Research in Advent Technology, Vol.7, No.4, April 2019

E-ISSN: 2321-9637

Available online at www.ijrat.org

$\mathrm{Nu}$ (TABLE 11)

\begin{tabular}{|c|c|c|c|c|c|c|c|c|c|}
\hline $\mathrm{M}$ & $\mathrm{I}$ & $\mathrm{II}$ & $\mathrm{III}$ & $\mathrm{IV}$ & $\mathrm{V}$ & $\mathrm{VI}$ & $\mathrm{VII}$ & VIII & IX \\
\hline 1 & 1.02339 & 0.974659 & 0.880292 & 0.943364 & 0.902247 & 1.03561 & 1.04272 & 1.02391 & 1.02442 \\
\hline 3 & 1.02244 & 0.97367 & 0.879222 & 0.941362 & 0.899662 & 1.03461 & 1.04168 & 1.02296 & 1.02348 \\
\hline 5 & 1.02088 & 0.97202 & 0.877443 & 0.93805 & 0.895388 & 1.03295 & 1.03994 & 1.0214 & 1.02191 \\
\hline Q1 & 0.05 & 0.15 & 0.3 & 0.05 & 0.05 & & & & \\
\hline Ec & 0.01 & 0.01 & 0.01 & 0.05 & 0.07 & So=1.5 & 2.5 & Gm=0.03 & 0.05 \\
\hline
\end{tabular}

Sh (TABLE 12)

\begin{tabular}{|c|c|c|c|c|c|c|c|c|c|}
\hline $\mathrm{M}$ & I & II & III & IV & V & VI & VII & VIII & IX \\
\hline 1 & 0.77875 & 0.830201 & 0.929689 & 0.870561 & 0.917735 & -0.318698 & -1.3749 & 0.779779 & 0.780808 \\
\hline 3 & 0.778278 & 0.829778 & 0.929352 & 0.871051 & 0.918759 & -0.318252 & -1.37342 & 0.779309 & 0.780339 \\
\hline 5 & 0.777487 & 0.829068 & 0.928786 & 0.871844 & 0.920434 & -0.317521 & -1.37099 & 0.77852 & 0.779553 \\
\hline Q1 & 0.05 & 0.15 & 0.3 & 0.05 & 0.05 & & & & \\
\hline Ec & 0.01 & 0.01 & 0.01 & 0.05 & $0.07(\mathrm{gm}=0.01)$ & So $=1.5$ & 2.5 & Gm=0.03 & 0.05 \\
\hline
\end{tabular}

\section{REFERENCES}

[1]. Abo-Eldahab, E.M and Elbarbary, E.M.E : Hall current effect on magnetohydrodynamic free convection flow past a semi-infinite vertical plate with mass transfer. Int. J. Eng. Sci., Vol.39, pp. 1641-1652 (2001).

[2]. Abdul Sattar. M.D and Mahmud Alam .M.D : Thermal diffusion as well as Transpiration effect on MHD free convection and mass transfer flow past on accelerated vertical porous plate. Int .J. of Pure and appl.Maths.V.25, No-6, PP.679-688 (1994).

[3]. Ajay Kumar Sing : MHD free convection and mass transfer flow with Hall effect, viscous dissipation , Joule heating thermal diffusion., Int J. Pure and Appl.Phys.V.41,PP-24-35 (2003).

[4]. Afify, A.A : MHD free-convective flow and mass transfer over a stretching sheet with chemical reaction. Int. J. Heat Mass transfer. Vol.40, pp.495-500 (2004).

[5]. Ali, M.E : On thermal boundary layer on a power-law stretched surface with suction or injection. Int. J. Heat Fluid Flow, Vol.16, No.4,pp.280-290 (1995).

[6]. Anderson, H.I, Hansen, O.R and Holmedal, B : Diffusion of a Chemically reactive species from a stretching sheet. Int. J. Heat \& Mass Transfer, pp. 37-659 (1994).

[7]. Anjalidevi, S.P. and Kandaswamy, R : Effects of chemical reaction heat and mass transfer on laminar flow along a semi infinite horizontal plate. Heat Mass Transfer, pp. 35465 (1999).

[8]. Anjalidevi, S.P. and Kandaswamy, R : Effects of chemical reaction heat and mass transfer on MHD flow past a semi infinite plate, $Z$. Angew. Math. \& Mech., pp. 80-697 (2000).

[9]. Biliana, B, Roslinda, N : Numerical solution of the boundary layer flow over an exponentially stretching sheet with thermal radiation. European journal of Scientific Research, Vol.33, N0.4, pp.710-717(2009).
[10]. Carragher, P, Crane, L.J : Heat transfer on continuous stretching sheet. Z. Angrew Math Mech, V.62, pp.564-565 (1982).

[11]. Chakrabarthi, A, Gupta, A.S : Hydromagnetic flow heat and mass transfer over a stretching sheet. Quart. Appl. Math. V.33, pp.73-78 (1979).

[12]. Chen, C.K and Char, M.I : Heat transfer of a continuous stretching surface with suction or blowing. J. Math. Ana. Appl., Vol.135, pp. 568-580 (1988)

[13]. Chin, D.T : Mass transfer to a continuous moving sheet electrode. J. Electrochem. Soc., pp.122-643 (1975).

[14]. Cowling T.G : Magnetohydrodynamics, Interscience Publishers, New York (1975).

[15]. Crane, L.J : Flow past a stretching sheet. Zeitschrift Angewandt Mathematik and Physik, pp:21-26 (1970).

[16]. Das, U.N, Deka, R.K and Soundalgekar, V.M : Effects of mass transfer on flow past an impulsively started infinite vertical plate with constant heat flux and chemical reaction. Forsch. Ingenieurwes, pp : 60-284 (1994).

[17]. Eckert.L.R.G and Drake R.M: Analysis of Heat and Mass Transfer, Mc Graw-Hill Book Co New York (1972).

[18]. Erickson, L.E, Fan, L.T and Fox, V.G : Heat and mass transfer on a moving continuous flat plate with suction or injection. Indust. Eng. Chem. Fundamentals, pp.5-19 (1966).

[19]. Fox, V.G, Erickson, L.E and Fan, L.T : Methods for solving the boundary layer equations for moving continuous flat surfaces with suction and injection. AICHE J., Vol.14, pp.726-736 (1968).

[20]. Gorla, R.S.R., 1978. Unsteady mass transfer in the boundary layer on continuous moving sheet electrode, J. Electrochem. Soc., pp : 125865.

[21]. Griffith, R.M : Velocity, Temperature and Concentration distribution during fibre 
International Journal of Research in Advent Technology, Vol.7, No.4, April 2019 E-ISSN: 2321-9637

\section{Available online at www.ijrat.org}

spinning. Ind. Eng. Chem. Fund., pp.3-245 (1964).

[22]. Grubka, L.J , Crane, L.J : Heat transfer characteristics of a continuous stretching surface with variable temperature. J. Heat transfer, V.107, pp.248-250 (1985).

[23]. Gupta, P.S, Gupta, A.S : Heat and mass transfer on a stretching sheet with suction or blowing. Can. J. Chem. Eng., V.55, pp.744746(1977).

[24]. Hsiao, K.L : Heat and mass transfer for electrical conducting mixed convection with radiation effect for visco elastic fluid past a stretching sheet. Journal of mechanics, Vol.24, No.2, pp.21-27(2008).

[25]. Jat, R.N , Santosh Chaudhary : MHD flow and heat transfer over a stretching sheet, Applied Mathematical Sciences, Vol.3, No.26, pp.1285-1294 (2009).

[26]. Magyari, E, Ali, M.E and Keller, B : Heat and mass transfer characteristics of the self-similar boundary layer flows induced by continuous surface stretched with rapidly decreasing velocities. Heat Mass Transfer, Vol.38, pp. 6574 (2001).

[27]. Malasetty. M.S and Gaikwad.S.N : Effect of cross diffusion on double diffusive convection in the presence of horizontal gradients, Int. J. Engg. V.40, pp 773-787 (2002).

[28]. McLeod, J.B. and Rajagopal, K.R : On the uniqueness of flow of a Navier-Stokes fluid due to a stretching boundary. Arch. Ration. Mech. Anal., pp.98-386 (1987).

[29]. Mohebujjaman, M, Tania, S. Khaleque and Samad, M.A : MHD heat transfer mixed convection flow along a vertical stretching sheet in presence of magnetic field with heat generation. International journal of Basic \& Applied Sciences, Vol.10, N0.2, pp.133-142 (2007).

[30]. Muthucumaraswamy, R. and Ganesan, P : On impulsive motion of a vertical plate with heat flux and diffusion of chemically reactive species. Forsch. Ingenieurwes, pp. 66-17 (2000).

[31]. Raghavendra Rao : Mixed convective heat and mass transfer flow in channels and ducts. Ph.D Thesis, S.K.University, Anantapur, India (2012).

[32]. Rana, M.A, Siddiqui, A.M and Ahmed, N : Hall effect on Hartmann flow and heat transfer of a burger's fluid. Phys. Letters A 372, pp. 562-568(2008).

[33]. Raptis, A and Perdikis, C : Viscous flow over a non-linearly stretching sheet in the presence of a chemical reaction and magnetic field. Int. J. Non-linear Mechanics, Vol.41, pp.527-529 (2006).

[34]. Reddaih P, Sreenivasa Reddy B and Prasada Rao DRV: Effect of dissipation and ThermoDiffusion on convective heat and mass transfer through a porous medium in a vertical channel maintained at Non uniform temperature . Acta Ciencia Indica Vol 34 M, No.4 1551-1565 (2008).

[35]. Sajid, M, Hayat, T and Asghar,S : Non-similar analytic solution for MHD flow and heat transfer in a third-order fluid over a stretching sheet. Int. J. of heat and mass transfer, Vol.50, pp.1723-1736 (2007).

[36]. Sakiadis, B.C : Boundary layer behavior on continuous solid surfaces: I, Boundary layer equations for two-dimensional and axis symmetric flow, AICHE J., Vol.7, No.1, pp.728 (1961).

[37]. Samad, M.A, Mohebujjaman, M : MHD heat and mass transfer free convection flow along a vertical stretching sheet in presence of magnetic field with heat generation. Research journal of Appl. Sciences, Engineering and technology, Vol.1, pp.98-106 (2009).

[38]. Seddeek, M.A : Heat and mass transfer on a stretching sheet with a magnetic field in a visco-elastic fluid flow through a porous medium with heat source or sink. Computational Material Science, Vol.38, pp.781-787(2007).

[39]. Shit, G.C : Hall Effects on MHD free convective flow and mass transfer over a stretching sheet. Int. J. of Appl. Math. and Mech., Vol.5, No.8, pp.22-38 (2009).

[40]. Sreenivasa Reddy.B : Thermo -diffusion effect on convective heat and mass transfer through a porous medium, Ph.D. thesis, S.K.University, Anantapur, India (2006).

[41]. Sreevani.M : Mixed convective heat and mass transfer through a porous medium in channels with dissipative effects, Ph.D thesis, S.K.University, Anantapur, India (2003).

[42]. Vajravelu, K. and Hadinicolaou, A : Convective heat transfer in an electrically conducting fluid at a stretching surface with uniform free stream. Int. J. Eng. Sci., Vol.35 pp.1237-1244 (1997).

[43]. Veena, P.H, Pravin, V.K, Shahjahan, S.M and Hippargi,V.B : Non-similar solutions for heat and mass transfer flow in an electrically conducting Visco- Elastic fluid over a stretching sheet embedded in a porous medium. Int. J. of Modern Mathematics, Vol.2, No.1, pp.9-26 (2007).

[44]. Watanabe T and Pop I, (1995): Hall effects on magnetohydrodynamic boundary layer flow over a continuous moving flat plate. Acta Mech. 108, pp. 35-47. 